\title{
The E3 ubiquitin ligase RNF115 regulates phagosome maturation and host response to bacterial infection
}

\author{
Orsolya Bilkei-Gorzo ${ }^{1,2,3}$, Tiaan Heunis ${ }^{1, \#}$, Daniela Fabrikova ${ }^{2}$, José Luis Marín-Rubio', \\ Julien Peltier ${ }^{1,3}$, Fiona Oakley ${ }^{4}$, Anetta Härtlova ${ }^{1,2,3^{*}}$, Matthias Trost ${ }^{1,3^{*}}$ \\ ${ }^{1}$ Biosciences Institute, Newcastle University, Newcastle upon Tyne, UK. \\ ${ }^{2}$ Wallenberg Centre for Molecular and Translational Medicine, Department of Microbiology \\ and Immunology at Institute of Biomedicine, University of Gothenburg, Gothenburg, Sweden. \\ ${ }^{3}$ MRC Protein Phosphorylation and Ubiquitylation Unit, University of Dundee, Dundee, \\ 10 Scotland, UK \\ ${ }^{4}$ Newcastle Fibrosis Research Group, Newcastle University, Newcastle upon Tyne, UK. \\ \#current address: Sir William Dunn School of Pathology, University of Oxford, Oxford, OX1 \\ 3RE, UK
}

${ }^{*}$ Correspondence to:

Matthias Trost, Biosciences Institute, Newcastle University, Newcastle upon Tyne, UK. matthias.trost@ncl.ac.uk

Anetta Härtlova, Wallenberg Centre for Molecular and Translational Medicine, University of

Gothenburg, Gothenburg, Sweden. anetta.hartlova@gu.se

Key words: phagosome, macrophage, ubiquitin, E3-ligase, RNF115 


\section{Summary}

Phagocytosis is a key process in innate immunity and homeostasis. After uptake, newly formed phagosomes mature by acquisition of endo-lysosomal enzymes. Macrophage activation by interferon-gamma (IFN- $\mathrm{y}$ ) increases microbicidal activity, but delays phagosomal maturation by an unknown mechanism. Using quantitative proteomics, we show that phagosomal proteins harbour high levels of typical and atypical ubiquitin chain types. Moreover, phagosomal ubiquitylation of vesicle trafficking proteins is substantially enhanced upon IFN-y activation of macrophages, suggesting a role in regulating phagosomal functions. Furthermore, we identified the E3 ubiquitin ligase RNF115, which is enriched on phagosomes of IFN- $\gamma$ activated macrophages, as an important regulator of phagosomal maturation. Loss of RNF115 protein or ligase activity enhanced phagosomal maturation and increased cytokine responses to Staphylococcus aureus, suggesting that both innate immune signalling from the phagosome and phagolysosomal trafficking are controlled through ubiquitylation. RNF115 knock-out mice show less tissue damage in response to $S$. aureus infection, indicating a role of RNF115 in inflammatory responses in vivo. In conclusion, RNF115 and phagosomal ubiquitylation are important regulators of innate immune functions during bacterial infections. 


\section{Introduction}

Phagocytosis is an essential component of the innate immune response against invading pathogens and tissue injury (Brown et al., 2015, Pauwels et al., 2017). It is an evolutionary conserved process by which microbes are internalised and delivered to the phagosome (Boulais et al., 2010). After internalization, the newly formed phagosome is constantly remodelled by fusion and fission processes with early and late endosomes and finally with the lysosome (Kinchen \& Ravichandran, 2008). These ultimate changes deliver the engulfed pathogen into the terminal degradative compartments known as phagolysosomes. This process is highly controlled and activation status of the macrophage changes the process significantly (Guo et al., 2019, Pauwels et al., 2019, Trost et al., 2009). As dysregulation of phagosome maturation can lead to infectious or inflammatory disease (Jain et al., 2019), it is of great of importance to understand how phagocytosis and phagosome maturation are controlled.

Ubiquitylation is an important post-translational modification that involves the covalent attachment of ubiquitin to (mostly) lysine $(\mathrm{K})$ residues of target proteins (Heap et al., 2017, Yau \& Rape, 2016). This process is catalysed by the sequential action of ubiquitinactivating and ligating enzymes (E1, E2 and E3) that can be reversed by deubiquitylating enzymes (DUBs) (Komander \& Rape, 2012, Ritorto et al., 2014). Ubiquitin itself can be ubiquitylated at one of its seven lysine residues and the N-terminus (M1, K6, K11, K29, K33, K48 and K63), leading to the assembly of polyubiquitin chains (Kulathu \& Komander, 2012). These chains lead to different biological outcomes: e.g. while K48 chains are associated with proteasomal degradation, K63 chains are known to be involved in cell signalling and trafficking (Erpapazoglou et al., 2014, Guo et al., 2019). Ubiquitin signalling is integral to almost all cellular processes in eukaryotes and thus, disorders or mutations in ubiquitin pathways result in a wide range of diseases.

Previous work has shown that polyubiquitin chains may associate with phagosomes (Lee et al., 2005). Moreover, several intracellular pathogens such as Legionella pneumophila, Shigella flexneri or Salmonella secrete ubiquitylation modifying enzymes (Ashida et al., 2014, Maculins et al., 2016, Qiu \& Luo, 2017), suggesting that ubiquitylation regulates key processes in phagosome biology and innate immunity (Dean et al., 2019). Here, we show that phagosomal proteins are highly ubiquitylated and interferon- $\gamma$ (IFN- $\gamma$ ) activation of macrophages substantially increases this further. We identified the E3 ligase Ring Finger Protein 115 (RNF115) which increasingly locates to phagosomes upon IFN-Y activation. Loss of RNF115 affected several phagosomal vesicle trafficking pathways and increased phagosomal maturation. Moreover, loss of RNF115 also increased cytokine responses and affected infection induced tissue damage in vivo. These results suggest a key role for RNF115 in phagosome functions and inflammatory responses. 
Results

Ubiquitylation is abundant on phagosomes and increased by IFN-Y activation

Recently, we and others have shown that IFN-y activation of macrophages reduces phagosomal maturation (Trost et al., 2009, Yates et al., 2007) (Figure 1A). Although it has been shown that increased reactive oxygen species (ROS) generated by the NADPH oxidase (NOX2) complex inhibit phagosomal proteolysis (Rybicka et al., 2010, Savina et al., 2006), the exact mechanism how IFN-y activation affects phagosomal maturation, is unknown.

As proteomics data showed that ubiquitin was enriched on phagosomes in response to IFN-y activation (Naujoks et al., 2016, Trost et al., 2009), we hypothesised that ubiquitylation may play a role in regulating phagosome function. We examined the presence of polyubiquitylation in total cell lysates (TCL) and on highly pure phagosomes (Hartlova et al., 2017) (Figure 1B). Immunoblots revealed significant enrichment of polyubiquitylated protein chains on phagosomes compared to TCL (Figure 1C). Moreover, inflammatory macrophage activation by IFN- $\gamma$ substantially enhanced ubiquitylation of phagosomal proteins. Ubiquitylation in the endo-lysosomal system is often considered to be primarily important for protein degradation. However, total ubiquitylation stays almost constant over the whole phagosomal maturation process of both resting and IFN- $\gamma$-treated macrophages (Figure 1D), suggesting that polyubiquitin chains may be heavily involved in endo-lysosomal processes themselves and may have other roles beside degradation, i.e. serving as signalling platforms (Guo et al., 2019).

In order to better understand the role of ubiquitylation of phagosomal proteins, we first determined which ubiquitin chain types were enriched on phagosomes. Comparative analysis using ubiquitin-chain type specific antibodies revealed that IFN- $\mathrm{Y}$ significantly induced K11, K48 and K63 polyubiquitylation chains on phagosomes (Figure 1E). As there are no selective antibodies for atypical chain types, we additionally used a quantitative targeted mass spectrometry approach, the AQUA ubiquitin Parallel Reaction Monitoring (PRM) assay (Figure 1F/G). This highly sensitive method enables the detection and quantification of endogenous ubiquitin chains (Heunis et al., 2020, Tsuchiya et al., 2013). The data confirmed increases of K11, K48 and K63 chains and additionally showed substantial amounts of non-canonical ubiquitin chains such as K27 and K33, whose biological function is less well understood (Kulathu \& Komander, 2012, van Huizen \& Kikkert, 2019) (Figure 1F). The phagosomal data shows substantial differences to the ubiquitin chains of TCL, within which K63, K48 and K11 chains dominate (Figure 1G). To further validate the PRM data, we performed deubiquitylase (DUB)-based analyses of phagosomal 115 ubiquitin chain composition using Ubiquitin Chain Restriction (UbiCRest) (Hospenthal et al., 2015). In these experiments, phagosomal extracts were treated with ubiquitin-chain specific 
DUBs such as USP2 (unspecific), vOTU (unspecific), Otulin (M1/linear), Cezanne (K11 >>K63), Trabid (K29, K33>K63) or AMSH-LP (K63) (Kristariyanto et al., 2015, Ritorto et al., 2014) and examined for the amount of monoubiquitin generated (Figure 1H).

Consistent with the PRM data, UbiCrest analysis revealed that $\mathrm{K} 11, \mathrm{~K} 48$ and K63-specific DUB Cezanne treatment hydrolysed most of polyubiquitin chains on phagosomes. Moreover, K63-specific DUB AMSH-LP treatment was the most effective in hydrolysing polyubiquitin chains on phagosomes. These data indicate that $\mathrm{K} 63$ polyubiquitylation might form the backbone of polyubiquitin chains on phagosome from which other ubiquitin chain types branch off. K63 polyubiquitylation is indeed well detectable by immunofluorescence microscopy around the phagosome of resting macrophages (Figure 11).

K63-linked polyubiquitylation of proteins have been described to lead to lysosomal degradation and contributes to signal transduction and protein-protein interactions (Wu \& Karin, 2015). Next, we tested whether polyubiquitin chains localize at the extra-luminal surface of phagosomes as opposed to sequestration within phagosomes. Highly pure phagosomes were treated with different DUBs to hydrolyse ubiquitin chains on intact phagosomes (Supplementary Figure 1A). This assay is based on the notion that ubiquitylated proteins within the phagosomal lumen resist ubiquitin chains hydrolysis when subjected to controlled DUBs exposure. Exposure of intact phagosomes to a general and unspecific DUB USP2 showed monoubiquitin in the supernatant but not in the lysate indicating that polyubiquitin chains are mainly localized on the cytoplasmic surface of phagosomes (Supplementary Figure 1B-C). IFN-y treatment increased the amount of hydrolysed polyubiquitin chains in the supernatants. The presence of vimentin on the phagosomal membrane demonstrated that phagosomes remained intact during DUB treatment. These data demonstrate that polyubiquitin chains are mainly localized on the extra-luminal surface of phagosomes, thereby allowing an interaction with other signalling proteins.

Altogether, these data indicate that polyubiquitylation is highly abundant on phagosomes of resting macrophages and significantly enhanced by IFN- $\gamma$ activation. 
bioRxiv preprint doi: $\mathrm{https}$ ://doi org/10.1101/2021.07.13.452284; this version posted July 15, 2021. The copyright holder for this preprint (which was not certified by peer review) is the author/funder, who has granted bioRxiv a license to display the preprint in perpetuity. It is made available under aCC-BY 4.0 International license.

\section{Figure 1}

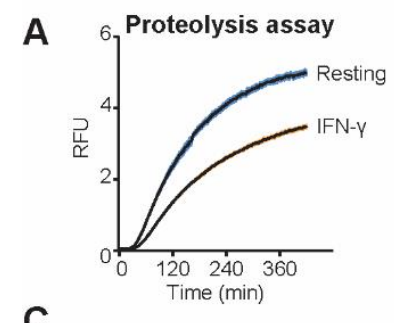

B Phagosome isolation
Polystyrene beads
Sucrose gradient

C

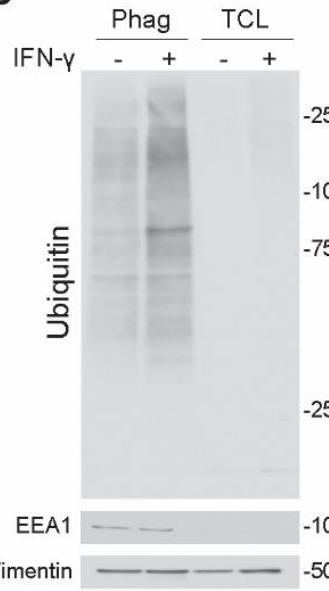

D

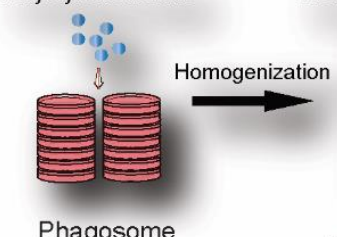

matu

0' $30^{\prime} 180^{\prime} \mathrm{TCL}$

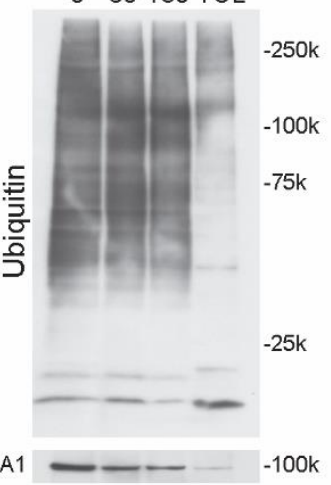

EEA1 - - - $-100 \mathrm{k}$

$-50 \mathrm{k}$ Vimentin $--50 \mathrm{k}$

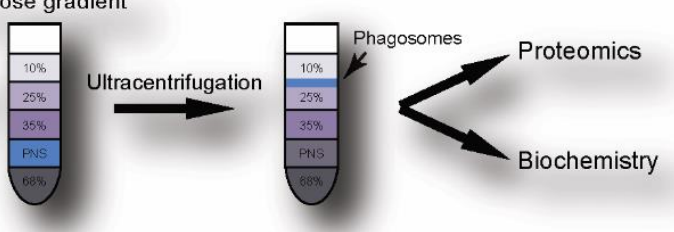

E

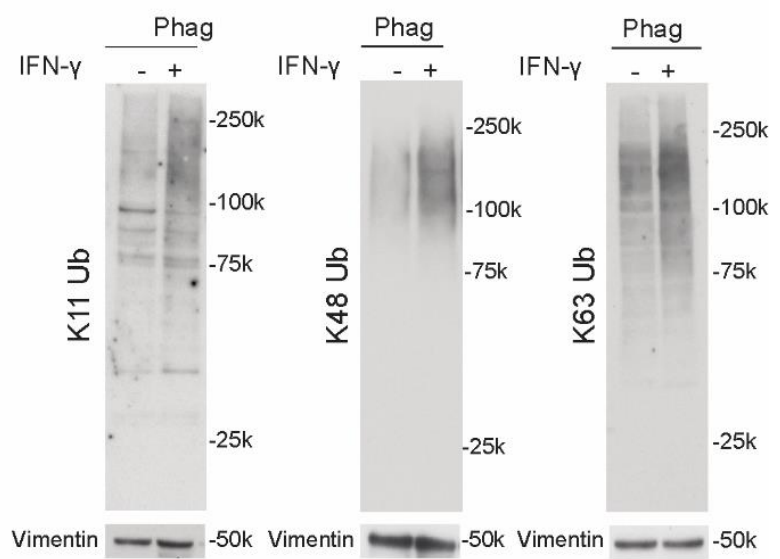

$\mathbf{F}$

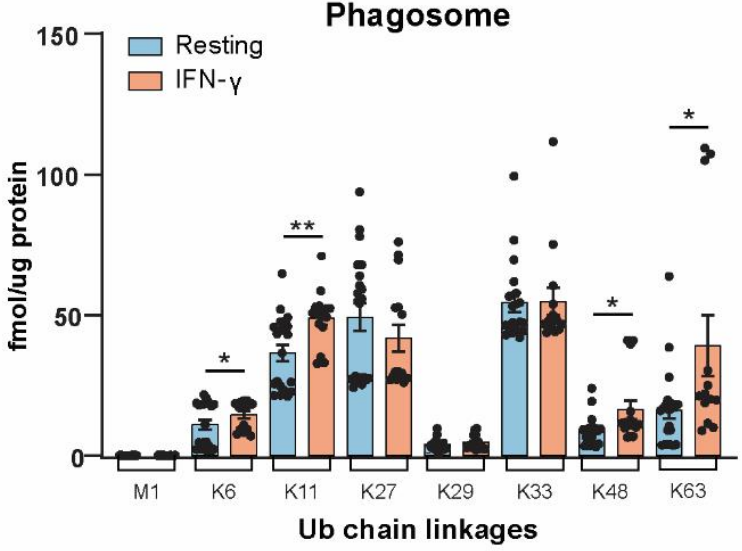

G

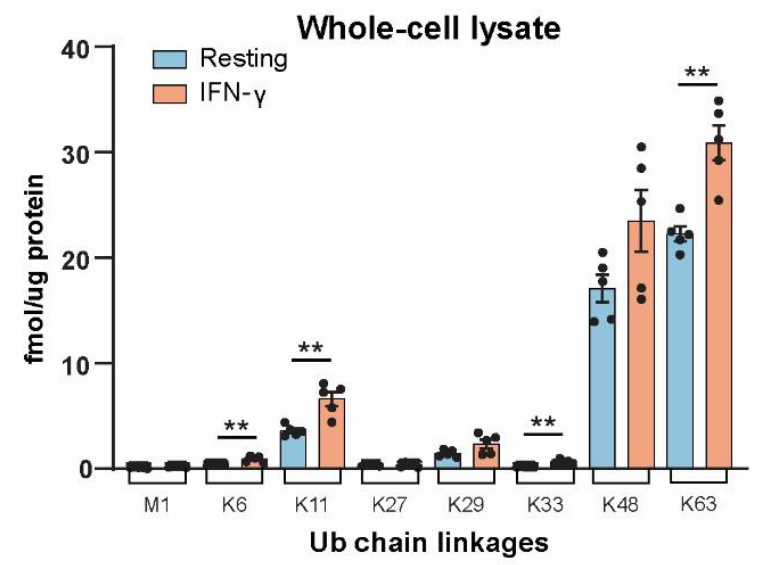

H

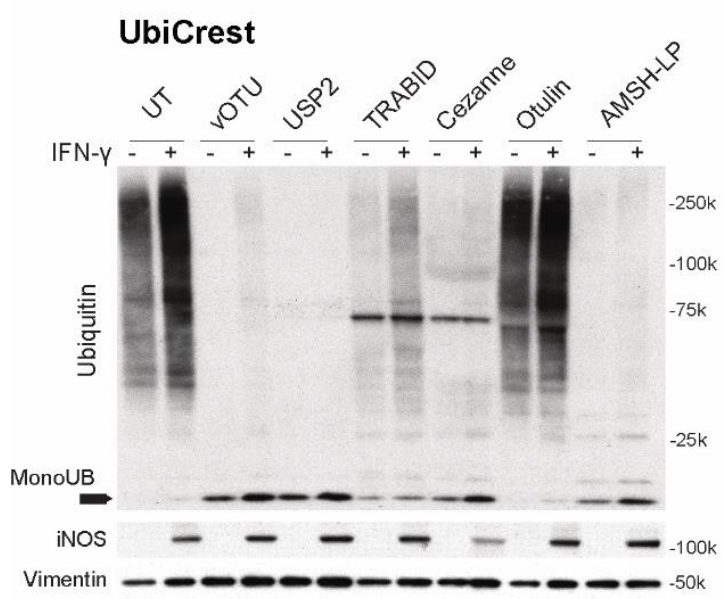

unspecific DUBs:

vOTU (K6, K11, K33, K48, K63) USP2 (M1, K11, K29, K48, K63) Trabid (K29, K33, K48, K63)

specific DUBs:

Cezanne (K11 > K48, K63)

Otulin (M1)

AMSH-LP (K63)

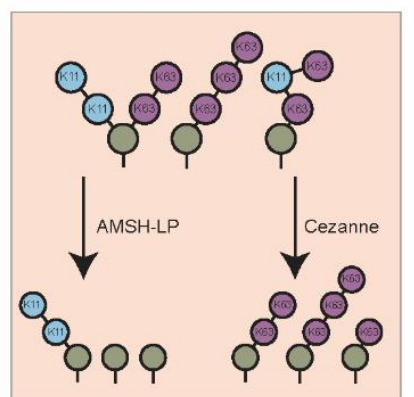

I

K63 polyubiquitin

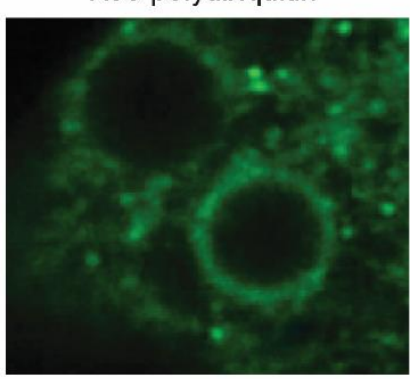


Figure 1: Characterisation of phagosomal ubiquitylation. (A) Intraphagosomal proteolysis assay shows that IFN- $\gamma$ activation of macrophages reduces phagosomal maturation. Shaded area represents SEM. (B) Workflow of phagosome isolation. (C-E) Western blots showing increased polyubiquitylation on phagosomes compared to Total Cell Lysate (TCL) and further increases by IFN-y activation (C, E). (D) Phagosomal ubiquitylation is not changing significantly over the maturation of the phagosome (30 min pulse, 0,30 , and $180 \mathrm{~min}$ chase). EEA1 serves as purity marker, Vimentin serves as loading control. Representative images of three replicates. (F) Ubiquitin AQUA PRM assay for phagosomes from RAW264.7 cells shows abundance of atypical chains and increases for K6, K11, K48 and K63 chains on phagosomes in response to IFN- $\gamma$ activation. As the experiment is complex and has inherent variability, five independent experiments of three biological replicates were combined. (G) Ubiquitin AQUA PRM assay of total cell lysates of RAW264.7

160 cells. Error bars represent SEM. ${ }^{*}=p<0.05 ;{ }^{* *}=p<0.01$ by paired two-tailed Student's t-test. (H) Ubiquitin Chain Restriction (UbiCRest) experiment removing polyubiquitin chains from phagosomal extracts using specific and unspecific DUBs. (I) Representative immunofluorescence micrograph showing that K63 polyubiquitin locates around the phagosome. Bead size: $3 \mu \mathrm{m}$.

Phagosome proteomics identifies increased ubiquitylation of vesicle trafficking proteins in response to IFN-Y

To further identify components of the ubiquitin system involved in the regulation of phagosome function in IFN- $\gamma$ activated macrophages, we analysed the phagosomal 170 proteome of resting and IFN- $\gamma$ activated macrophages by a quantitative mass spectrometry approach (Dill et al., 2015, Guo et al., 2019) (Figure 2A, Supplementary Table 1). We identified a several proteins of the ubiquitin system (Figure 2B). We observed increased abundance of E1 and E2 enzymes, as well as E3 ligases, suggesting that the increased polyubiquitylation is a result of increased enzyme abundance rather than reduced deubiquitylation. Particularly, since DUB abundance was overall not decreased.

After tryptic digestion, ubiquitylation leaves a di-glycine (Gly-Gly) tag on the $\varepsilon$ amino group of lysines. Commercial antibodies allow the enrichment of these peptides for mass spectrometric analysis. We performed such a Gly-Gly pulldown of ubiquitylated peptides from $300 \mu \mathrm{g}$ of phagosomal extracts ( 200 cell culture dishes) per replicate.

180 Quantitative mass spectrometry revealed 478 ubiquitylation sites on phagosomal proteins (Supplementary Table 2). Comparing the abundance of these Gly-Gly-modified peptides with the protein abundance changes on the total protein level showed that most proteins were overall more ubiquitylated in response to IFN- $y$. Proteins that were up-regulated in protein abundance and protein ubiquitylation were mostly involved in inflammatory and 185 interferon-regulated responses, e.g. the nitric oxide synthase Nos2. However, interestingly, a large number of proteins were not or mildly regulated by protein abundance but changed highly in ubiquitylation, including the endo-lysosomal Rab7 and the NADPH oxidase 2 subunit Cybb (Figure 2C). Gene Ontology (GO) analysis revealed that these proteins were 
bioRxiv preprint doi: https://doi.org/10.1101/2021.07.13.452284; this version posted July 15, 2021. The copyright holder for this preprin (which was not certified by peer review) is the author/funder, who has granted bioRxiv a license to display the preprint in perpetuity. It is made available under aCC-BY 4.0 International license.

mostly involved in vesicle trafficking on lysosomal, endosomal and Golgi membranes as well as members of the v-ATPase complex (Figure 2D).

Figure 2

A

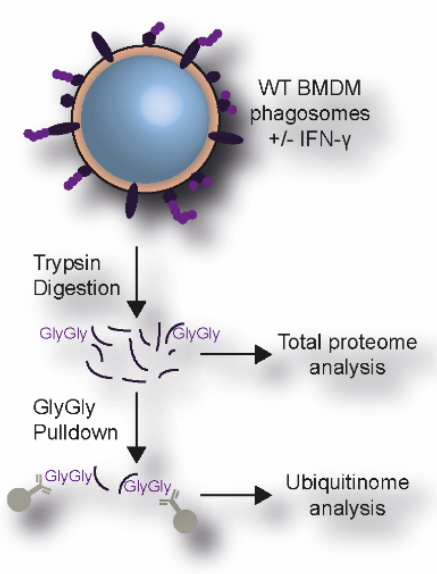

C

\begin{tabular}{|c|c|c|c|}
\hline $\begin{array}{l}\text { E3 } \\
\text { Gene }\end{array}$ & $\begin{array}{c}\log 2 \\
\text { IFNMT }\end{array}$ & Gene & $\begin{array}{c}\log 2 \\
\text { IFNMT }\end{array}$ \\
\hline $\mathrm{Cbl}$ & -0.15 & Rnf20 & -0.87 \\
\hline Dtx2 & -0.77 & Rnf25 & -0.95 \\
\hline Dtx31 & 4.42 & Rnf114 & -0.37 \\
\hline Herc6 & IFN only & Rnf115 & IFN only \\
\hline Huwe1 & -0.75 & Rnf130 & 0.18 \\
\hline Itch & -0.16 & Rnf149 & 2.75 \\
\hline $\mathrm{Kcmf1}$ & -0.06 & Rnf213 & 2.38 \\
\hline March5 & Rest only & Rnf220 & -1.77 \\
\hline Mgrn1 & -0.75 & Trim25 & 0.43 \\
\hline Mkrn2 & -1.13 & Trim33 & -0.99 \\
\hline Nsmce2 & IFN only & Trip12 & -0.22 \\
\hline Ppil2 & -1.01 & Ubr4 & 0.24 \\
\hline $\mathrm{Rb} \times 1$ & -0.77 & Uhrf1 & -3.74 \\
\hline Rlim & -1.68 & Wwp2 & -0.45 \\
\hline Rnf2 & -0.44 & Znrf1 & -0.51 \\
\hline Rnf13 & -0.24 & Znrf2 & -0.75 \\
\hline Rnf19b & IFN only & & \\
\hline
\end{tabular}

B

\begin{tabular}{|c|c|c|c|c|c|}
\hline $\begin{array}{l}\text { Ubi \& ULM } \\
\text { Gene }\end{array}$ & $\begin{array}{l}\log 2 \\
\text { IFNMT }\end{array}$ & $\begin{array}{l}\text { DUBs } \\
\text { Gene }\end{array}$ & $\begin{array}{c}\log 2 \\
\text { IFNMT }\end{array}$ & $\begin{array}{l}\text { E2 } \\
\text { Gene }\end{array}$ & $\begin{aligned} & \log 2 \\
=N M W T & \end{aligned}$ \\
\hline Ubc & 0.54 & OTUB1 & 0.56 & \multirow{2}{*}{\multicolumn{2}{|c|}{$\begin{array}{l}\text { Ube2c Rest only } \\
\text { Ube2d } 1 / 2 / 3 \quad 1.10\end{array}$}} \\
\hline ISG15 & 4.79 & Stambp & 0.63 & & \\
\hline Sumo1 & 0.29 & Uchl3/4 & 0.03 & Ube213 & 2.16 \\
\hline Sumo2/3 & -0.98 & Uchl5 & -0.03 & Ube2n & 1.03 \\
\hline Ufm1 & 0.56 & Usp3 & -1.37 & Ube2k & -0.04 \\
\hline Ubl3 & 0.93 & Usp5 & 0.32 & Ube $2 q 1$ & -0.16 \\
\hline Ubl5 & 1.17 & Usp7 & 0.02 & Ube2q2 & 0.99 \\
\hline E1 & $\log 2$ & Usp8 & 0.62 & Ube2v1/2 & 0.58 \\
\hline Gene & IFNMT & Usp9x & 0.29 & & \\
\hline Uba1 & 0.75 & Usp14 & -0.27 & & \\
\hline Uba5 & 0.21 & Usp18 & 3.50 & & \\
\hline
\end{tabular}

D

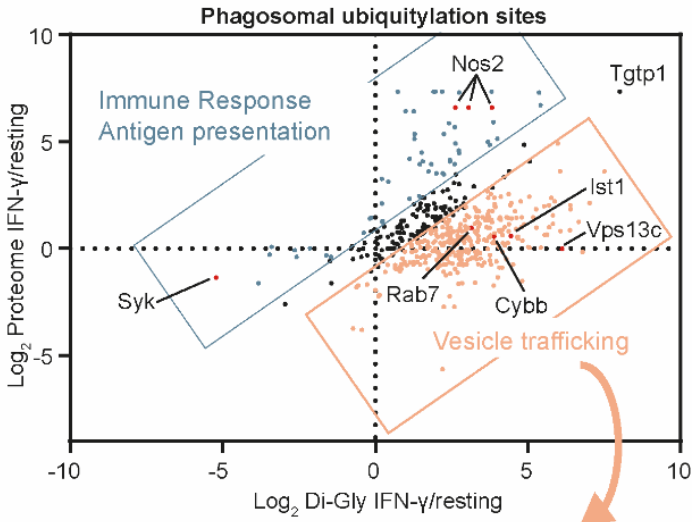

E

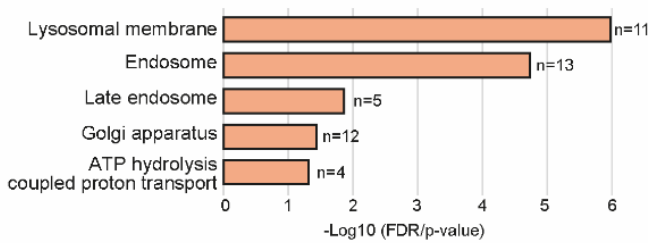

F

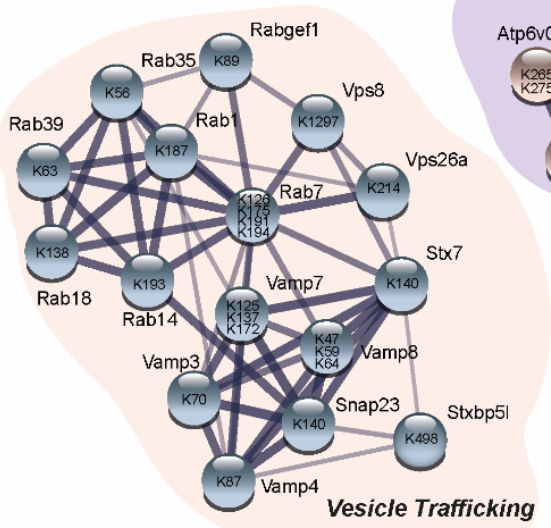

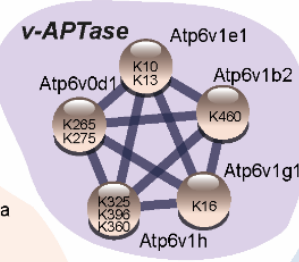

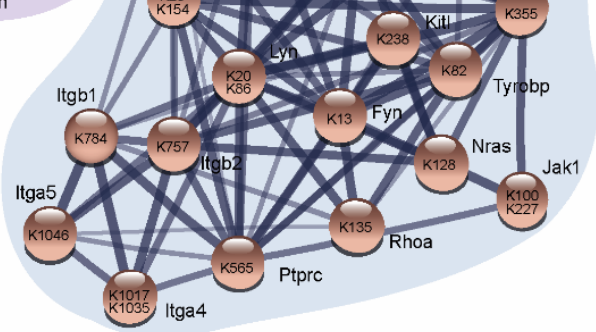

Figure 2: Proteomics shows that IFN-y activation increases ubiquitylation of innate immunity and vesicle trafficking proteins. (A) Workflow. 30 min old phagosomes were isolated from RAW264.7 cells. Phagosome extracts were tryptically digested for total proteome analysis or Gly-Gly pulldowns were performed to enrich for ubiquitylated peptides. (B \& C) Selected phagosomal proteins of the ubiquitin system (Ubiquitin \& ubiquitin-like modifiers (ULM), E1, E2 and E3 and deubiquitylases (DUBs)) and their abundance changes in response IFN- $\gamma$ activation. (D) Combined analysis of total proteome and Gly-Gly proteomics data sets of phagosomes from untreated and IFN-Y activated RAW264.7 cells. (E) Gene Ontology (GO) Analysis of proteins that were highly ubiquitylated in response to 
IFN-y activation but did not change $(-0.5>$ Log $2<0.5)$ significantly on the protein level. $(F)$ Selected networks of proteins and their ubiquitylation sites from data in (D). Level of shading of edges indicates interaction confidence.

While some of the ubiquitylation sites were conserved between substrates, for example the sites on the cytosolic tails of Integrins Itgb1 and Itgb2, others appeared to be spread over the whole sequence. Interestingly, ubiquitylation of many of the vesicle trafficking proteins such as the VAMP proteins appears in functional domains, suggesting that these modifications will affect the binding of their SNARE domains (Supplementary figure 2A). Moreover, we realised that ubiquitylation affects recognition of antibodies in Western Blot experiments. Rab7, for example, a master regulator of endo-lysosomal trafficking (Bucci et al., 2000), is highly ubiquitylated in the C-terminal part of the protein. As this is the area against which antibodies were raised, they do not recognise the ubiquitylated form. Only after removal of ubiquitylation using recombinant DUBs, the protein "appears" from TUBE pulldowns (Supplementary figure 2B). Altogether, this dataset provides an important resource of ubiquitylation targets in the endo-lysosomal system.

E3 ligase RNF115 locates to the phagosome and loss of RNF115 affects vesicle trafficking to the phagosome

Next, we hypothesised that the increased ubiquitylation on the phagosome was mediated by specific IFN-y activated E3 ligases. We identified five significantly upregulated E3 ligases on the phagosome in response to IFN-y stimulation, including the ISG15 E3 ligase Herc6 (Figure 3A). The upregulated E3 ligases included Dtx3l, which forms a complex with PARP9 and plays a role in DNA damage and antiviral responses (Zhang et al., 2015); RNF149, an uncharacterised RING ligase; RNF213, a 591 kDa multi-domain protein which has been implicated in angiogenesis, Moyamoya disease and the ubiquitylation of LPS of intracellular bacteria (Otten et al., 2021), and the RING E3 ligase RNF115 (also called BCA2 or Rabring7) (Figure 3A).

As RNF115 was previously reported to bind to Rab7, and play a role in receptor trafficking and anti-viral host response by interfering with endo-lysosomal pathways (Li et al., 2020, Miyakawa et al., 2009, Nityanandam \& Serra-Moreno, 2014, Zhang et al., 2020), we tested if RNF115 regulated phagosomal functions.

To analyse the association of RNF115 with phagosomes, immunoblot analysis of phagosomal and TCL fractions confirmed enrichment of RNF115 on phagosomes of IFN- $y$ activated and resting macrophages compared to corresponding TCLs of resting 235 macrophages (Figure 3B). Consistent with immunoblot data, immunofluorescence microscopy analysis revealed RNF115 translocation on phagosomes by partly co-localising 
with Lysosomal-associated membrane protein 1, LAMP1, in IFN- $\gamma$ activated macrophages (Figure 3C).

Figure 3
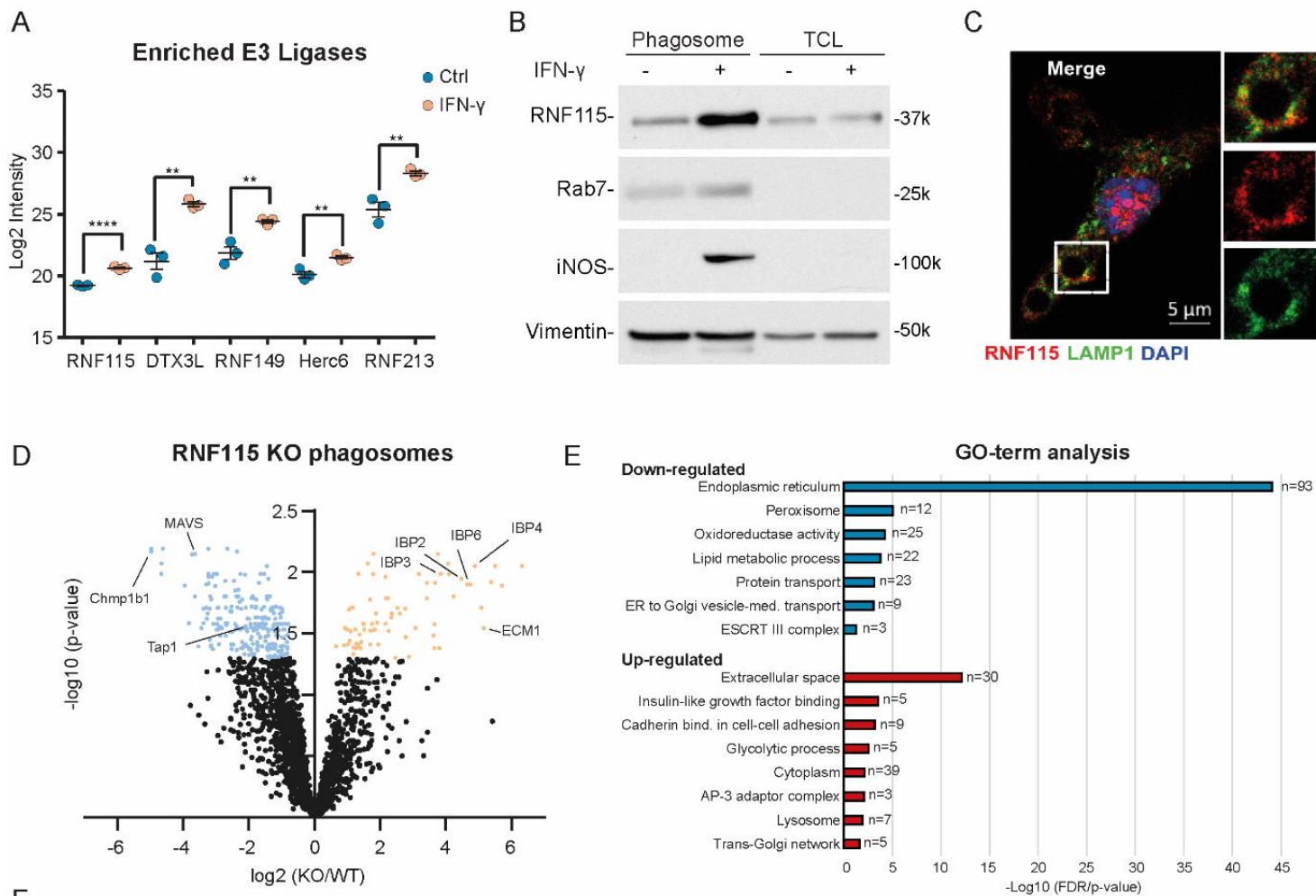

$\mathrm{F}$
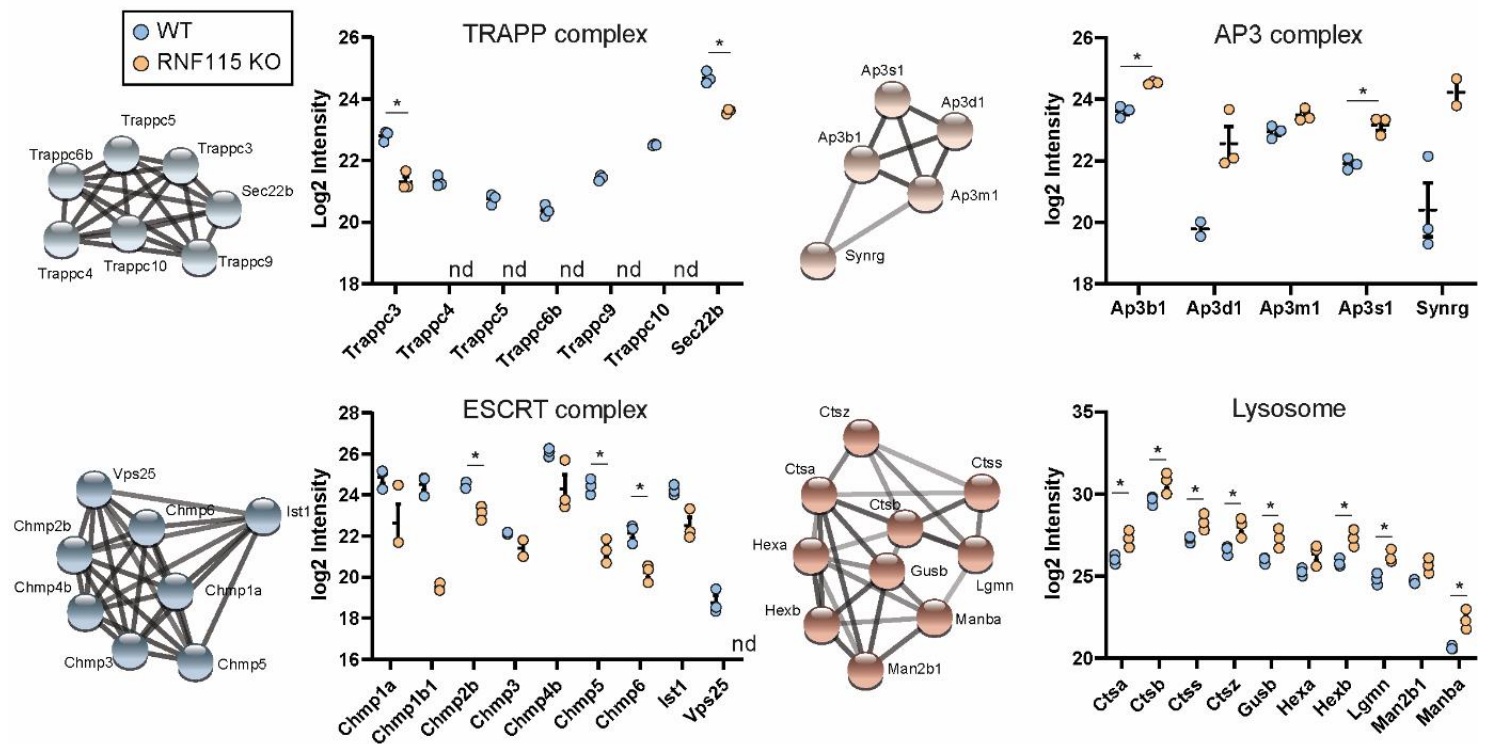

Figure 3: Ubiquitin E3 ligase RNF115 is enriched on phagosomes of IFN-Y activated macrophages and loss of RNF115 affects several phagosomal functions. (A) Proteomics intensity levels of selected phagosomal E3 ligases enriched upon IFN- $\gamma$ activation. (B) Western blot of phagosomal and TCL extracts showing enrichment of RNF115 on phagosomes of RAW264.7 cells and its increased abundance in response to IFN-Y activation. Rab7 serves as purity control, iNOS as activation control and vimentin as loading control. Representative image of three replicates. (C) Representative immunofluorescence micrograph showing RNF115 co-localising with LAMP1 around the phagosome in murine BMDMs. Scale bar equals 5 microns. (D) Volcano plot of proteomics data of resting WT and 
RNF115 KO BMDM phagosomes. Selected proteins are highlighted. (E) Gene Ontology (GO) analysis of up- and down-regulated proteins from (D). (F) Proteomics intensity data of selected protein complexes derived from (D). Error bars represent SEM. nd $=$ not detected. ${ }^{*}=\mathrm{p}<0.05$.

To further distinguish whether RNF115 is present on the extra-luminal surface of phagosomes or if it is an intraluminal cargo, we treated isolated phagosomes with increasing amounts of trypsin to digest phagosome-associated proteins in a dose-dependent manner (Supplementary figure 3A). The analysis revealed that exposure to $0.5 \mu \mathrm{g}$ trypsin led to a significant reduction in RNF115, similar to phagosome-associated Rab5, whereas the internal membrane protein LAMP1 resisted trypsin treatment. These data indicate that RNF115 localizes to the extra-luminal surface of phagosomes.

To characterise the role of RNF115 on the phagosome, we generated a RNF115 knock-out (KO) cell line in RAW264.7 macrophages using CRISPR/Cas9 genome editing techniques. The efficiency of $\mathrm{KO}$ was confirmed by sequencing and immunoblot analyses (Supplementary figure 3B). To determine whether RNF115 is involved in the regulation of phagocytosis, we measured the uptake of green fluorescent carboxylated particles in WT and RNF115 KO macrophages. Ablation of RNF115 or loss of E2 binding of RNF115 did not affect phagocytic uptake of carboxylated particles (Supplementary Figure 3C) or bacterial uptake (Supplementary Figure 3D).

In order to get a systems level understanding of the effects of loss of RNF115, we isolated phagosomes from WT and RNF115 KO macrophages and performed proteomics analysis (Figure 3D, Supplementary Table 3). The phagosome, as part of the endo-lysosomal system, interacts with practically all vesicle trafficking pathways of the cell and therefore allows identifying specific pathways. Loss of RNF115 affected several vesicle trafficking pathways including an increase of lysosomal and secretory proteins in the phagosome and a reduction of proteins of the ER and the peroxisome (Figure 3E). Of the secreted proteins, the Insulin-like growth factor-binding proteins (IGFBPs), appeared particularly retained in the endo-lysosomal system upon RNF115 loss, suggesting a role of RNF115 in correctly trafficking these proteins. Moreover, loss of RNF115 also decreased recruitment of the ESCRT complex highlighting the role in ubiquitylation for the functional role of this complex.

Other protein complexes affected by loss of RNF115 were the Transport Protein Particle (TRAPP) complex which is involved in ER-Golgi and Golgi-plasma membrane trafficking (i.e. secretion) (Kim et al., 2016). TRAPP was significantly less abundant on RNF115 KO phagosomes and may explain the retention of cargo that was meant to be secreted (Figure 3F). On the other hand, the AP-3 complex, that shuttles proteins to the lysosome, is enriched in RNF115 KO phagosomes. Finally, we also identified 
a significant upregulation of lysosomal proteins in the RNF115 KO phagosome, suggesting that loss of RNF115 also increases phagosomal maturation (Figure 3F).

Altogether, this data indicates that loss of RNF115 affects ER-Golgi, secretory and lysosomal vesicle trafficking pathways to the phagosome. Overall, this data shows that ubiquitylation plays an important role in protein and vesicle trafficking.

Loss of RNF115 increases phagosomal maturation

Since loss of RNF115 affected abundance of lysosomal proteins on the phagosome, we investigated next whether RNF115 was involved in the regulation of phagosomal maturation. We measured phagosomal proteolytic activity and $\mathrm{pH}$ in $\mathrm{WT}$ and RNF115 KO cells using real-time quantitative fluorescent DQ-green BSA-coated particles and beads coated with pHrodo dyes that fluoresce brightly in an acidic environment (Figure 4A-B). Ablation of RNF115 enhanced both phagosomal proteolysis and acidification indicating that RNF115 is a negative regulator of phagosome maturation. These data were further validated by complementing RNF115 KO cells with RNF115-HA that reversed enhanced phagosomal proteolytic activity of $\mathrm{KO}$ macrophages. To test whether RNF115 regulates phagosomal proteolysis in a ligase-dependent manner, we mutated W259A as this tyrosine has been shown to be essential for E2 binding in other RING ligases (Hodson et al., 2014). This "ligase dead" mutant indeed increased proteolytic activity in macrophages similarly to the $\mathrm{KO}$, demonstrating that RNF115 E3 ligase activity is needed for regulation of phagosome maturation (Figure 4C).

Altogether, these data indicate that RNF115 is a negative regulator of phagosomal maturation and its ubiquitin ligase activity is required for its effect on phagosome maturation. 
Figure 4

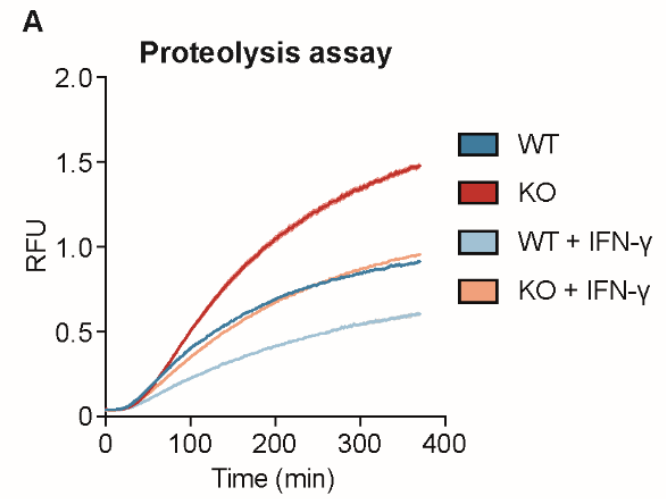

C

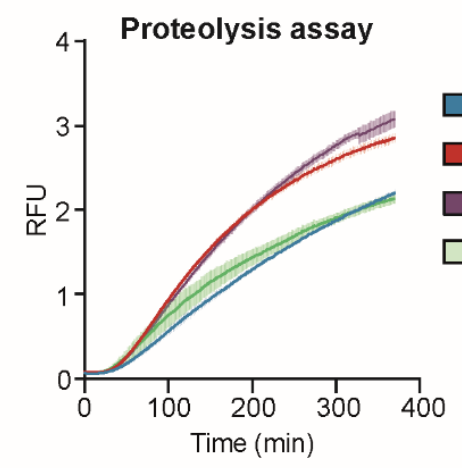

E
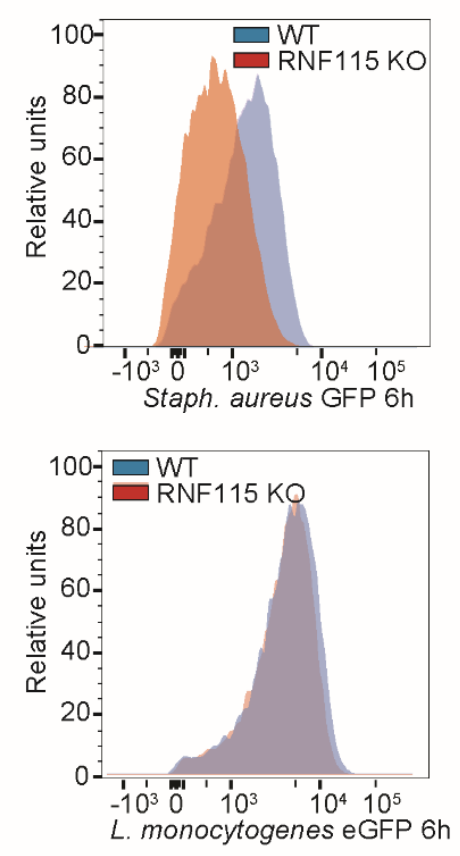

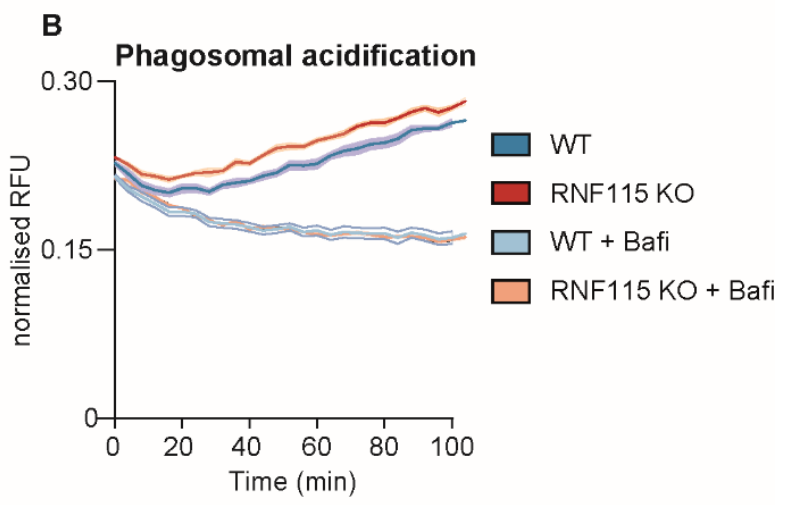

D

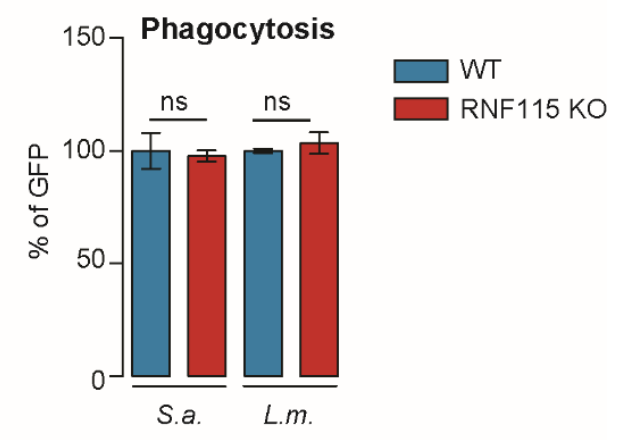

310 Figure 4: Loss of RNF115 increases phagosomal proteolysis and enhances innate immune responses to intraphagosomal bacteria. (A-B) Intraphagosomal proteolysis and acidification assays show that loss of RNF115 increases phagosome maturation in BMA cells. Bafi = Bafilomycin (C) Complementing the RNF115 KO with WT RNF115 or a W259A mutant which in unable to bind to E2 enzymes, shows that RNF115 ligase activity is required for the increase of phagosome maturation. Shaded area represents SEM. (D) Phagocytosis assay of live Staphylococcus aureus (S.a.) or Listeria monocytogenes (L.m.) shows that loss of RNF115 does not affect uptake. (E) Flow-cytometry based assay to measure degradation 
of intracellular GFP-expressing bacteria shows that loss of RNF115 increases degradation of $S$. aureus, but not $L$. monocytogenes $6 \mathrm{~h}$ after infection. $\mathrm{MOI}=10 .(\mathrm{F}, \mathrm{G}) \mathrm{qPCR}$ and ELISA data shows that loss of RNF115 increases TNF- $\alpha$ and IL6 expression and secretion after infection with $S$. aureus, but not $L$. monocytogenes. $\mathrm{MOI}=10$. Error bars represent SEM. ${ }^{*}=\mathrm{p}<0.05 ;{ }^{* *}=\mathrm{p}<0.01 ;{ }^{* * *}=\mathrm{p}<0.001$ by paired two-tailed Student's t-test.

\section{Loss of RNF115 enhances innate immune responses from the phagosome}

The main function of the phagosome emerges from its ability to effectively digest internalized cargo via phagosome-lysosomal fusion. Next, we asked whether RNF115 deficiency promotes enhanced bacterial killing using the Gram-positive infection models Staphylococcus aureus and Listeria monocytogenes. While $S$. aureus is primarily considered an extracellular pathogen, several studies including our data suggest that $S$. aureus also replicates and survives within macrophages and that this maybe important to the pathogenesis of this organism (Flannagan et al., 2016, Pidwill et al., 2020). For instance, it has been found that phagosomal maturation is required for $S$. aureus-induced TNF- $\alpha$ production (Ip et al., 2010). L. monocytogenes on the other hand, will quickly escape into the cytosol by the use of the haemolysin Listeriolysin O (LLO) (Nguyen et al., 2019). The analysis revealed that RNF115 KO deficiency did not impact uptake of either pathogen (Figure 4E). However, degradation of phagosomal $S$. aureus was significantly increased in the KO, while cytosolic Listeria were not affected.

Moreover, RNF115 KO macrophages elicited a higher induction of Tnfa and I/6 pro-inflammatory genes and higher levels of cytokine secretion in response to $S$. aureus compared to WT, while responses to L. monocytogenes were comparable (Figure 4F-G). This suggests that loss of RNF115 affects specifically innate immune signalling from the phagosome, while signalling from the cytosol is unaffected.

Altogether this data indicates that loss of RNF115 induces increased innate immune responses to bacterial pathogens from the phagosome. 
Figure 5

A

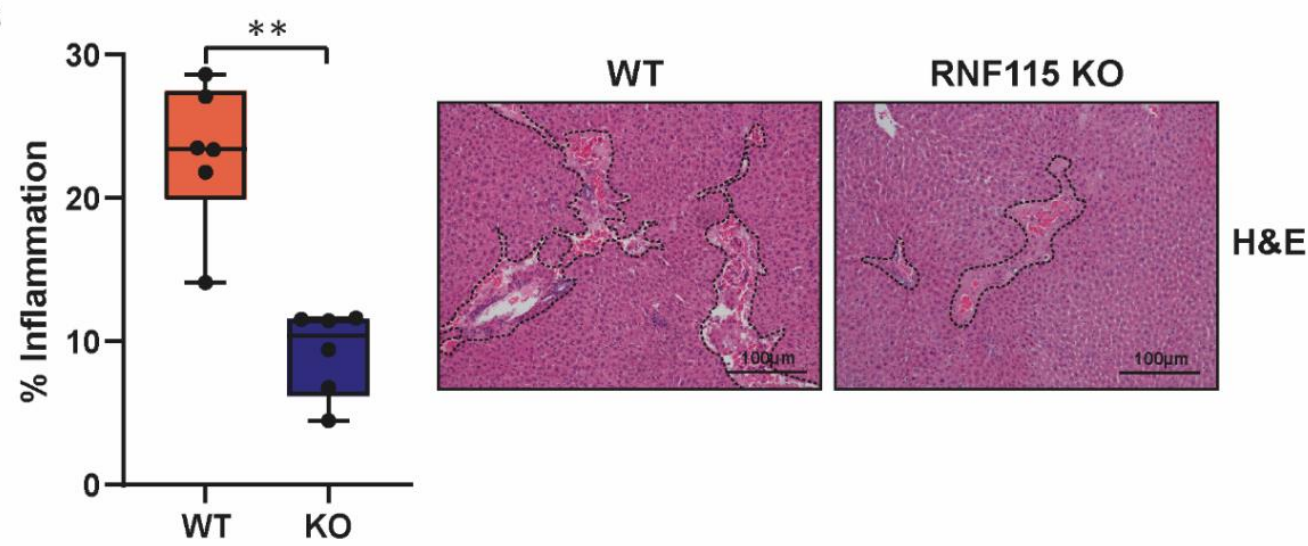

B
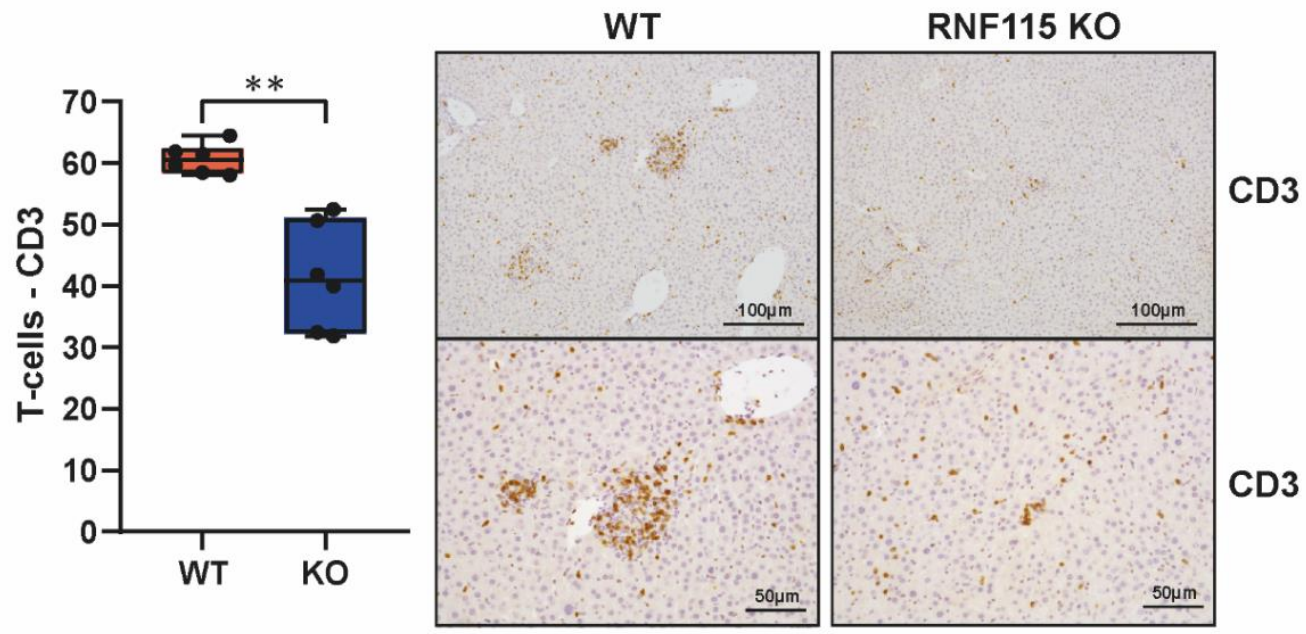

C
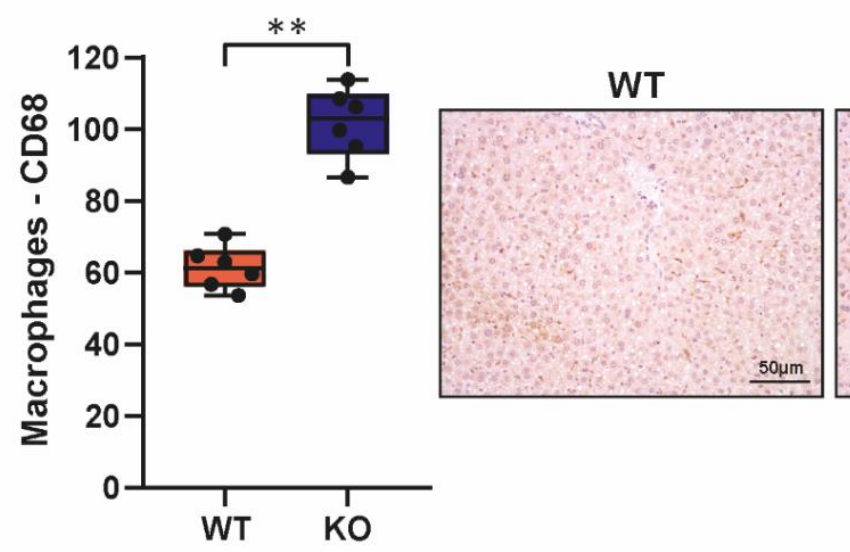

RNF115 KO

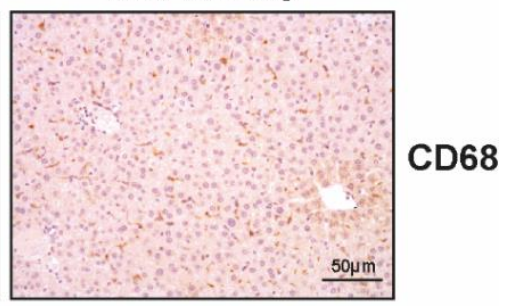

Figure 5: Loss of RNF115 reduces inflammatory response and tissue damage to $S$.

aureus infection in vivo. A) Quantification of the hepatic lesion area in the livers from wildtype (WT) and RNF115 KO (KO) mice after 48 hours infection with $S$. aureus. Haematoxylin and eosin (H\&E)-stained liver sections of one representative animal per genotype are shown on the right, dotted line depicts the damaged area. (B) Average cell counts per high power field (HPF) of CD3 positive T-cells, and C) CD68 positive macrophages in the livers from wild-type (WT) and RNF115 KO (KO) mice after 48 hours infection with $S$. aureus. Representative immunohistochemistry sections are shown on the right. Groups were compared using an unpaired two-tailed t-test. The statistical significance of the comparisons is indicated as follows: ${ }^{* *}, \mathrm{P}<0.01$. Each dot represents an individual animal. 


\section{Loss of RNF115 reduces tissue damage and inflammatory response to $S$. aureus infection in vivo}

RNF115 KO mice generated within this project have no obvious phenotype and breed with Mendelian ratios. We infected six WT and RNF115 KO mice with $S$. aureus through tail-vein injection. After 48 hours, mice were humanely sacrificed, and livers were analysed by immunohistochemistry (IHC). Data showed that loss of RNF115 significantly reduced infection/inflammation dependent tissue damage (Figure 5A) and recruitment of CD3 T-cells (Figure 5B). On the other hand, RNF115 KO mice showed higher levels of CD68-stained macrophages (Figure 5C), suggesting a higher level of tissue repair after infectious insult. These data indicate that loss of RNF115 enhances bacterial clearance and reduces tissue damage in response to pathogenic bacteria in vivo. 


\section{Discussion}

Phagosomes are key organelles in innate immunity. As large intracellular vesicles, they are in continuous interaction with other vesicle trafficking pathways of the cell and in constant change. Here, we show for the first time that ubiquitylation plays a major role in regulating vesicle trafficking pathways to the phagosome and, thereby, regulating phagosome functions.

While ubiquitylation has been studied for many years in the endosomal system for its role in receptor sorting and multi-vesicular body (MVB) formation (Frankel \& Audhya, 2018, Haglund \& Dikic, 2012), and significant work has gone into characterising bacterial ubiquitin enzymes of intracellular pathogens such as Legionella (Vozandychova et al., 2021), little is known about the role of endogenous ubiquitylation on the phagosome. In 2005 , it was shown that ubiquitin accumulates around the phagosome and that loss of E1 activity resulted in accumulation of Fc-receptors, suggesting a defect in sorting the receptors (Lee et al., 2005). Recently, it was shown that loss of the K63 specific E2 ligase Ubc13 (Ube2n) affects phagosome maturation leading to accumulation of apoptotic bodies in C. elegans (Liu et al., 2018). Furthermore, we have shown that receptor ubiquitylation can serve as a scaffold for proinflammatory signalling from the phagosome (Guo et al., 2019).

Our data indicates that phagosomes are not only rich in ubiquitylation but they also contain significant amounts of atypical chains such as K27 and K33 chains whose biological function is poorly understood (Kulathu \& Komander, 2012, van Huizen \& Kikkert, 2019). It appears that K27 may also serve as a scaffold to recruit specific signalling pathways, as recent data showed that $\mathrm{K} 27$ ubiquitylation of BRAF by ITCH - which is also enriched on phagosomes - regulates MEK-ERK signalling (Yin et al., 2019). Interestingly, the UbiCRest experiment showed that most ubiquitylation on the phagosome is removed by using the K63-specific DUB AMSH-LP. This suggests that K63 chains may present the basis for chain architecture of polyubiquitylated phagosomal proteins. Future work will be required to characterise the roles of atypical chain types in phagosome biology.

It needs to be noted that IFN- $y$ activation also increases phagosomal ISGylation 400 (data not shown) which also leaves a Gly-Gly tag on proteins after tryptic digest. It is therefore possible that some of the sites identified were ISGylated rather than ubiquitylated. However, estimations of ubiquitin (8.6 kDa, log2 intensity 30) and ISG15 (17.8 kDa, log2 intensity of 25) abundance suggests that ubiquitin is about 50 -70fold more abundant on the phagosome than ISG15. This indicates that most of the Gly-Gly sites identified are indeed ubiquitylation sites. Chain-type specific TUBEs (Heap et al., 2017, Hjerpe et al., 2009) or the use of LB-Pro (Swatek et al., 2018, Swatek et al., 2019), an ISG15 specific protease, may provide more insights into the substrates of specific ubiquitin chain types in the future. 
Nonetheless, our data provides a first glance at ubiquitylated proteins from the phagosome or any other organelle in the endo-lysosomal system. The diversity of substrates is astonishing as is the fact that many ubiquitylation sites on functional domains of proteins, such as the SNARE domains of VAMP proteins, will disrupt protein-protein interactions. Further characterisation of the ubiquitylation of these proteins is hampered by the observation that antibodies often do not bind to recognition sequences anymore once they are ubiquitylated. In this paper, for example, we show that ubiquitylated RAB7 is not detectable by Western Blot and only after deubiquitylation, the protein appeared in the blot. The use of tandem ubiquitin binding entities (TUBEs) (Hjerpe et al., 2009) pulldown with subsequent deubiquitylation may be a successful strategy to avoid difficulties.

We identified more than 30 E3 ligases on the phagosome. So far, only RNF19b (NKLAM) has been identified as a E3 ligase with functions regulating phagosome functions (Lawrence \& Kornbluth, 2012, Lawrence \& Kornbluth, 2018). Lawrence et al showed that loss of $\mathrm{RNF19b}$ led to reduced killing of phagocytosed $E$. coli as well as reduced inflammatory responses. Our data showed RNF19b to be unique to phagosomes of IFN- $\gamma$ activated macrophages, supporting the findings of this exciting work. In the future, it would be of interest to study the effects of loss of RNF19b on phagosome function and proteome.

In this paper, we followed up the role of RNF115 (BCA2, Rabring7) on the phagosome. RNF115 was identified as a binding partner of Rab7 (Mizuno et al., 2003) and involved in endosomal sorting of EGFR (Smith et al., 2013). RNF115 has been shown highly expressed in invasive breast cancers (Burger et al., 2005). Recent work placed RNF115 as a regulator of inflammatory responses by showing that it may SUMOylate IKBa (Colomer-Lluch \& Serra-Moreno, 2017) and that it may polyubiquitylate MAVS and MITA/STING (Zhang et al., 2020), two proteins important for detection of cytosolic viral RNA and DNA, respectively. Both MAVS and STING are present on phagosomes. While STING was only slightly reduced, MAVS was $\sim 12$-fold downregulated upon loss of RNF115. This contradicts Zhang et al findings, as one would expect increased MAVS and STING levels in the RNF115 KO. Moreover, total protein 435 levels of STING and MAVS were not affected in total cell lysates of BMDMs (data not shown). Nonetheless, our findings suggest that RNF115 may indeed somehow regulate MAVS, however, more likely through protein/vesicle trafficking from the mitochondria rather than direct K48 ubiquitylation.

Our data indicates, that RNF115 has a multitude of functions. The main differences that we detected in RNF115 KO macrophages was a dysregulation of innate immunity and vesicle trafficking pathways, suggesting that RNF115 ubiquitylates vesicle trafficking proteins. Similar to Zhang et al, who showed that loss of RNF115 affected immune responses to HSV-1 (Zhang et al., 2020), innate immune responses were affected in our experiments. However, in our model, only for signalling from pathogens within the phagosome. 
445 While RNF115 may affect signalling pathways directly, it may also be possible that loss of RNF115 affects the time that innate immune receptors spend signalling from the phagosomal membrane by abolishing proper recycling and sorting of these immune receptors. More work will be needed to characterise the molecular targets of RNF115 in order to understand the exact function of this E3 ligase in innate immunity.

Overall, this work is the first in depth characterisation and quantification of ubiquitin on phagosomes. Our novel approach allowed an unbiased analysis of ubiquitin chains enriched on phagosomes and the identification of ubiquitylated phagosomal proteins. Our results demonstrate the importance of ubiquitylation in vesicle trafficking and indicate the regulatory function in immune signalling. We identified the E3 ubiquitin ligase, RNF115, a Rab7 interacting protein, as a new regulator of phagosomal maturation. We show that its E3 ligase activity is essential for its ability to affect phagosomal proteolysis and it is a negative regulator of pro-inflammatory cytokine induction from phagosome upon $S$. aureus infection. 


\section{Cell culture}

RAW264.7 were obtained from ATCC. BMA3.1A7 cells were kindly provided by Kenneth Rock (Dana Farber Center, Boston, US). Both cell lines were maintained in Dulbecco's modified eagle medium (DMEM), $10 \%$ (v/v) heat-inactivated foetal bovine serum (FBS), 1 $\mathrm{mM}$ L-Glutamine, $100 \mathrm{U} / \mathrm{ml}$ penicillin, $100 \mu \mathrm{g} / \mathrm{ml}$ streptomycin. Cells were maintained in this media under $5 \% \mathrm{CO}_{2}$ at $37^{\circ} \mathrm{C}$ in a water-saturated incubator. Cells were tested every 3 months for mycoplasma infection.

\section{Mice}

Wild-type C57BL/6J and C57BL/6NTac mice were obtained from Charles River and Taconic, respectively. RNF115 KO (RNF115-DEL562INS28-EM1-B6N) C57BL/6NTac mice were kindly provided by the Mary Lyon Centre, MRC Harwell, UK. Mice were bred under appropriate UK home office project licenses.

\section{Isolation and culturing of bone-marrow derived macrophages}

Bone marrow cells were collected from femurs and tibia of 6 - to 8-week old C57BL/6J or C57BL/6NTac wild-type mice. Collected cells were treated with red blood cell lysis buffer (155 $\mathrm{mM} \mathrm{NH}_{4} \mathrm{Cl}, 12 \mathrm{mM} \mathrm{NaHCO}_{3}, 0.1 \mathrm{mM} \mathrm{EDTA}$ ) and plated on untreated $10 \mathrm{~cm}$ cell culture dishes (BD Biosciences) in IMDM (Gibco) containing 10\% heat-inactivated FBS, 100 units/ml penicillin/streptomycin (Gibco) and 15\% L929 conditioned supplement. After $24 \mathrm{~h}$, the cells in supernatant were transferred to untreated $10 \mathrm{~cm}$ Petri dishes (BD Biosciences) for 7 days for the differentiation into bone marrow-derived macrophages (BMDMs) (Heap et al., 2021). 


\section{Antibodies}

The following antibodies were purchased from Cell Signaling technologies: Vimentin (\#5741). EEA1 (\#2411), Rab7 (\#9367), iNOS (\#2977). Antibodies purchased from Abcam were the following: Cathepsin D (ab75852), RNF115 (ab187642) and Histone H3 (ab176842). Total-ubiquitin antibody was purchased from DAKO (ZO458). Ubiquitin chainspecific antibodies were a kind gift from Genentech. Tubulin (GTX628802) was purchased from Genetex, Flag-M2 (F3165) from Sigma Aldrich. RNF115 antibodies were produced in sheep by the antibody group of the Division of Signal Transduction Therapy (DSTT), MRCPPU, University of Dundee and are available through https://mrcppureagents.dundee.ac.uk/

\section{Proteins}

All proteins in this work were kindly provided by Dr Axel Knebel, Protein Purification and Assay Development Team (PPAD), MRC-PPU or by the Protein Purification Team headed by James Hastie, DSTT, MRC-PPU. E3 ligases produced were RNF115 and RNF115 W259A. Deubiquitylase enzymes produced were: Otulin, AMSH-LP, USP2, vOTU, Cezanne, TRABID. The Tandem Ubiquitin Binding Entity (TUBE) was HALO-Ubiquilin/NZF2. Proteins were expressed as $\mathrm{His}_{6}$-tagged fusion proteins in E. coli followed by a PreScission proteinase cleavage tag.

\section{Phagosome isolation}

Phagosomes were isolated according to previous methods (Hartlova et al., 2017, Trost et al., 2009). In short, carboxylated polystyrene beads of $0.8 \mu \mathrm{m}$ (Estapor/Merck) were internalised by macrophages for 30 minutes at $37^{\circ} \mathrm{C}, 5 \% \mathrm{CO}_{2}$. For chase experiment cells were washed with pre-warmed PBS and fresh growth media for additional incubation times. After incubation, cells were washed in ice-cold PBS and scraped into $50 \mathrm{ml}$ Falcon tubes while 
kept on ice. Non-internalized beads were removed and cells were re-suspended in $1 \mathrm{ml}$ of HB homogenization buffer $(8.55 \%(\mathrm{w} / \mathrm{w})$ sucrose, $2.5 \mathrm{mM}$ imidazole, $\mathrm{pH} 7.4)$ supplemented with inhibitors of proteases (Complete, Roche) and phosphatases (1.15 mM sodium molybdate, $4 \mathrm{mM}$ sodium tartrate dihydrate, $1 \mathrm{mM}$ freshly prepared sodium orthovanadate, 5

$515 \mathrm{mM}$ glycerophosphate, all Sigma), and $100 \mathrm{mM} \mathrm{N}$-Ethylmaleimide (NEM) to block DUBs. Cells were homogenized and mixed with $68 \%$ sucrose solution $(68 \%(\mathrm{w} / \mathrm{w})$ sucrose, $2.5 \mathrm{mM}$ imidazole, $\mathrm{pH} 7.4$ ). A sucrose gradient was prepared by layering $68 \%$, lysate, $35 \%, 25 \%$ and $10 \%$ sucrose solution. The gradients were centrifuged in an ultracentrifuge (Beckman Coulter) at $24000 \mathrm{rpm}(72300 \times \mathrm{g})$ for 1 hour at $4 \stackrel{\circ}{\circ}$. After the centrifugation, the latex beads containing phagosomes were visible by showing a blue band between the $10 \%$ and the $25 \%$ sucrose layers. The phagosomes were collected into new ultracentrifuge tubes using a thintipped transfer pipette. Phagosomes from two gradients were combined into one ultracentrifuge tube and were then washed by adding cold PBS until the volume reaches 1 $\mathrm{cm}$ below the top of the tube. After mixing, phagosomes were pelleted by centrifugation at $52515000 \mathrm{rpm}(28400 \times \mathrm{g})$ for $15 \mathrm{~min}$ at $4^{\circ} \mathrm{C}$. After removing the supernatant, the phagosomes were either used for experiments or stored at $-80^{\circ} \mathrm{C}$.

\section{Phagosome functional assays}

The fluorogenic assays for phagosomal proteolysis and acidification were adapted from 530 Russell laboratory (Yates et al., 2009). Cells were seeded into a 96 well plate at $1 \times 10^{5}$ cells per $\mathrm{ml} 24 \mathrm{~h}$ prior to the experiment. Carboxylate silica beads ( $3 \mu \mathrm{m}$, Kisker Biotech) were conjugated with DQ red BSA (Molecular Probes) or pHrodo (Molecular Probes) and incubated for 3 minutes at 1:100 in binding buffer (1\% FBS in PBS pH 7.5) with seeded macrophages at $37^{\circ} \mathrm{C}$. Solution was replaced with warm binding buffer and cells were

535 immediately measured at $37^{\circ} \mathrm{C}$. Real-time fluorescence was measured using a SpectraMax Gemini EM Fluorescence Microplate Reader (Molecular Devices), set as maximal readings per well to allow reading time intervals of $2 \mathrm{~min}$. The excitation/emission wavelengths were 
590/620 (DQ red BSA), 650/665 (Alexa Fluor 640), 560/585 (pHrodo) for the proteolysis or acidification assay. Plots were generated from the ratios of signal/control fluorescence. Error bars were generated from standard error of the mean of 6 replicates.

\section{Phagocytosis assay}

Cells were seeded into a 96 well plate at $1 \times 10^{5}$ cells per $\mathrm{ml} 24 \mathrm{~h}$ prior to the experiment. Alexa Fluor 488 BSA-coated silica beads $(1 \mu \mathrm{m}$, Kisker Biotech) were incubated at 1:100

545 dilution for 60 minutes at $37^{\circ} \mathrm{C} .100 \mu$ trypan blue per well was used to quench signal of non-internalized particles. After removing trypan blue cells were measured using SpectraMax Gemini EM Fluorescence Microplate Reader (Molecular Devices), set at excitation/emission wavelengths 495/519 nm.

\section{Coupling HALO-Ubiquilin/ $\mathrm{NZF}_{2}$ to HALO resin}

$200 \mu \mathrm{l}$ packed HaloLink resin (Promega) was washed three times in HALO-binding buffer (50 mM Tris, $150 \mathrm{mM} \mathrm{NaCl}, 0.05 \% \mathrm{NP}-40,1 \mathrm{mM}$ DTT). Beads were incubated with $820 \mu \mathrm{g}$ $\mathrm{HALO}-U b i q u i l i n / \mathrm{NZF}_{2}$ in $1 \mathrm{ml} \mathrm{HALO-binding} \mathrm{buffer} \mathrm{for} 16 \mathrm{~h}$ at $4^{\circ} \mathrm{C}$ in a rotating wheel. Beads were washed three times in HALO-binding buffer and used immediately or stored up to two weeks at $4^{\circ} \mathrm{C}$ in HALO-binding buffer supplemented with $0.01 \%$ sodium azide.

\section{HALO-Ubiquilin/NZF 2 pull-down assay}

To capture ubiquitin chains from cell extracts $10 \mu \mathrm{l}$ of packed beads were incubated with $1 \mathrm{mg}$ cell extract protein. For enrichment of ubiquitylated proteins from phagosomal proteins after magnetic beads isolation, $60 \mu \mathrm{g}$ phagosomal extract was incubated with $10 \mu \mathrm{l}$ of packed beads. Samples were incubated for $16 \mathrm{~h}$ at $4^{\circ} \mathrm{C}$ at end-over-end mixing and beads were washed 3 times with IP washing buffer $50 \mathrm{mM}$ Tris, $150 \mathrm{mM} \mathrm{NaCl}, 1 \%$ Triton-X 100. If 
no other treatment was required slurry was denatured by LDS sample buffer. Beads were transferred to SpinX tubes (Corning) to collect sample for SDS/PAGE.

\section{Immunoblot analysis}

Phagosomes or cells were lysed directly in $2 x$ Laemmli buffer (with $5 \% \beta$-mercaptoethanol) and subjected to SDS-Page using 4-12\% NuPage gels (Invitrogen) and immunoblotted to PVDF membrane. Membranes were blocked for $1 \mathrm{~h}$ at RT in $5 \%(\mathrm{w} / \mathrm{v})$ skim milk in TBS-T

$\left(0.1 \%\right.$ Tween-20) and subsequently incubated with primary antibodies overnight at $4^{\circ} \mathrm{C}$. Horseradish-peroxidase (HRP) conjugated secondary antibodies were incubated with membranes, after which proteins were detected using ECL and X-ray films. Immunoblots were quantified using ImageJ software.

\section{CRISPR/Cas9 BMA line production}

Using the CRISPR/Cas9 genome editing system was performed with gRNAs in BMA cell line targeting exon 1 of RNF115. Transfection was carried out using Fugene HD (Promega) reagent and $1 \mu \mathrm{g}$ of gRNA and Cas9 D10A. Transfection was carried out overnight after which selection was induced using puromycin $(1 \mu \mathrm{g} / \mathrm{ml})$ for $48 \mathrm{~h}$. Cells were subcloned to 580 maintain a monoclonal knockout population. Clones were validated using sequencing, immunoblotting and immunoprecipitation.

\section{E2 enzyme screening assay}

WT RNF115 $(0.4 \mu \mathrm{M})$ or RNF115 mutant (W259A) $(0.4 \mu \mathrm{M})$ were incubated with $0.2 \mu \mathrm{M}$

$585 \mathrm{UBE} 1,1 \mu \mathrm{M}$ of indicated E2 enzyme and $5 \mu \mathrm{M}$ of FLAG-ubiquitin in ubiquitin assay buffer containing $2 \mathrm{mM} \mathrm{ATP}$ in a total reaction volume of $30 \mu \mathrm{l}$. Samples were incubated at $30^{\circ} \mathrm{C}$ for $1 \mathrm{~h}$ while shaking $1000 \mathrm{rpm}$ after which the reaction was terminated by the addition of 
LDS. The samples were subjected to SDS/PAGE and the formation of ubiquitin chains by RNF115 was assessed by immunoblotting with anti-FLAG.

\section{Deubiquitylase assay with endogenous proteins}

Phagosomes were lysed in lysis buffer (50 mM Tris, $150 \mathrm{mM} \mathrm{NaCl}, 1 \%$ Triton-X 100, $5 \mathrm{mM}$ DTT) and incubated with deubiquitylating enzymes at $30^{\circ} \mathrm{C}$ for 1 hour. Enzyme concentrations unless otherwise stated were: USP2 $(2 \mu \mathrm{M})$, vOTU $(2 \mu \mathrm{M})$, TRABID $(5 \mu \mathrm{M})$,

Cezanne $(5 \mu \mathrm{M})$, AMSH-LP $(2 \mu \mathrm{M})$, Otulin $(5 \mu \mathrm{M})$. To stop reaction 1x LDS (Invitrogen) was added and immunoblotting was conducted.

\section{Cell lysis and immunoprecipitation}

Cells were washed in ice-cold PBS two times after which they were lysed on ice in lysis

buffer $\left(50 \mathrm{mM}\right.$ Tris- $\mathrm{HCl} \mathrm{pH}$ 7.5, $150 \mathrm{mM} \mathrm{NaCl}, 1 \%$ Triton-X 100, 1x Complete $^{\mathrm{TM}}$ protease inhibitor cocktail tablet (Roche), $0.1 \mathrm{mM}$ EDTA, 0,1 mM EGTA, $50 \mathrm{mM} \mathrm{NaF}, 5 \mathrm{mM}$ sodiumpyrophosphate, $1 \mathrm{mM}$ sodium orthovanadate, $10 \mathrm{mM}$ sodium b-glycerophosphate, $100 \mathrm{mM}$ N-ethylmaleimide (NEM). After lysis in appropriate volume samples were incubated on ice for 20 minutes and then centrifuged at $350 \mathrm{xg}$ for $20 \mathrm{~min} 4^{\circ} \mathrm{C}$. Supernatant was acquired and protein concentration was determined according to the Bradford method using Protein Assay Dye Concentrate.

Required volume of protein G-Sepharose beads were washed three times with PBS before addition of antibody at 1:1 ratio. The final volume was adjusted with PBS to give 2:1 ratio to ensure sufficient mixing of beads. Beads were shaken for 2 hours at $4^{\circ} \mathrm{C}$ and then washed 2 more times with PBS. For $15 \mu \mathrm{l}$ of protein G-Sepharose beads $1 \mathrm{mg}$ protein lysate was used and incubated for $4 \mathrm{~h}$ while shaking at $4^{\circ} \mathrm{C}$. Samples were washed 3 times in washing buffer (50 mM Tris- $\mathrm{HCl} \mathrm{pH} 7.5,150 \mathrm{mM} \mathrm{NaCl}, 1 \%$ Triton-X 100). Finally, beads were resuspended in 1x Laemmli buffer and used for immunoblotting. 


\section{Immunofluorescence}

615 BMDM cells were seeded on coverslips $24 \mathrm{~h}$ before experiment and activated with IFN- $\mathrm{\gamma}$, if needed. Carboxylate silica beads ( $3 \mu \mathrm{m}$, Kisker Biotech) were added at 1:1000 dilution for 30 minutes after which slides were washed with PBS 3 times. 4\% PFA was added at RT 20 minutes, after which cells were permeabilized by $0.1 \%$ Triton-X 100 in PBS for 5 min RT. Blocking was done in 5\% BSA in PBS for 30 min at RT after which primary antibodies were added RNF115 (1:200) o/n at 4ํㅡ. After washing 3 times Alexa Fluor 594 coupled anti-rabbit (Life Technologies) was added at a dilution of $1: 500$ for $1 \mathrm{~h}$ at RT. DAPI was used to counterstain DNA and slides were mounted in Mowiol.

\section{qPCR}

625 BMA cells were seeded at a final concentration of $0.2 \times 10^{6}$ into a 12-well plate. After stimulation, total RNA was extracted using RNeasy Purification Kit (Qiagen, Cat. No. 74104). Using iScript cDNA synthesis kit form Bio-Rad (170-8891) $0.5 \mu \mathrm{g}$ RNA was reverse transcribed. PCR was performed in a 384 well plate and each $10 \mu \mathrm{l}$ reaction contained $0.5 \%$ cDNA, $0.5 \mu \mathrm{M}$ primers and $5 \mu \mathrm{l}$ SSo Fast EvaGreen Supermix from Bio-Rad (172-5204) according to manufacturer's instruction on a CFX384 machine (Bio-Rad). Normalisation of mRNA was done to $18 \mathrm{~S}$ and the relative gene expression levels, in comparison of control (unstimulated cells (UT)), were calculated according to the comparative cycle threshold. Levels of mouse RS18, IL -6 and TNFa mRNA were detected by validated QuantiTect primer assays 144 (Qiagen).

\section{Bacterial strains and culture conditions}

All experiments with Listeria monocytogenes were performed with strain EDGe (original stock from Hao Shen, University of Pennsylvania) and its hly (EJL1) derivative were grown in brain heart infusion (BHI) broth. Staphylococcus aureus RN6390 (kind gift from Tracy 
640 Palmer, Newcastle University) were grown in Tryptone Soy Broth (TSB). Bacteria were incubated at $37^{\circ} \mathrm{C}$ with constant rotation. All bacteria were used at mid-exponential phase for infection experiments.

\section{Bacterial infection}

645 Bacterial cultures were grown to mid-exponential phase and pelleted by spinning at 7,000 $\times \mathrm{g}$ for 5 min, washed in PBS and subsequently resuspended in DMEM containing 10\% FBS. Bacteria was added at $\mathrm{MOI} 10$ to BMA cells for 30 minutes. Afterwards cells were washed and resuspended in DMEM containing 10\% FBS and $5 \mathrm{mM}$ gentamycin for $30 \mathrm{~min}$. Once again media was removed cells washed and resuspended in DMEM containing $10 \%$ FBS for indicated time points after which cells were lysed as needed.

CFUs were determined by lysing cells at indicated time points in $0.1 \%$ Triton-X 100 in PBS from which serial dilutions were produced and plated for $\mathrm{o} / \mathrm{n}$ incubation at $37^{\circ} \mathrm{C}$. On the next day bacterial colonies were counted and CFU was determined.

\section{In vivo mouse infection}

Approval to conduct research on animals was granted by the United Kingdom Home Office (PC123A338) and Newcastle University. Adult wild-type and RNF115 KO C57BL/6NTac mice were fed a standard rodent diet and kept under controlled environmental conditions (12-h light-dark cycle).

S. aureus RN6390 was cultured in tryptic soy broth (TSB) until an optical density of $0.8-1.0$ at $600 \mathrm{~nm}$ was reached. The cells were harvested by centrifugation $(10,000 \times \mathrm{g}, 2 \mathrm{~min})$ and washed twice with PBS $\mathrm{pH}$ 7.4. S. aureus RN6390 cells were resuspended in PBS pH 7.4 and used for infections. Each animal received $2 \times 10^{6} \mathrm{CFU}$ of $S$. aureus RN6390 in $0.2 \mathrm{ml}$ of PBS pH 7.4 via intravenous injection in the lateral tail vein. Cell 
counts of the inoculum were verified by serial dilution and plating on TSB agar plates. The plates were subsequently incubated at $37^{\circ} \mathrm{C}$ for 24 hours, after which CFU were determined.

The mice were euthanized 48 hours after the infection via cervical dislocation, and livers were harvested for immunohistochemistry. For immunohistochemistry, liver samples were fixed in $4 \%$ formaldehyde in PBS $\mathrm{pH} 6.5$. Tissue samples were processed using automated procedures to impregnate and subsequently embed samples in paraffin wax.

\section{Immunohistochemistry}

Formalin-fixed and paraffin-embedded liver sections were cut into $3-\mu \mathrm{m}$ thick sections, deparaffinised in xylene and rehydrated in ethanol and water. The sections were stained with Mayer's haematoxylin and eosin using standard protocols and inflammatory foci in the tissue section was counted at X10 magnification.

For immunohistochemical detection, endogenous peroxidase activity was blocked using hydrogen peroxide. Tissue sections were subjected to heat-induced antigen retrieval in 680 EDTA, pH 8.0 for CD3 and sodium citrate buffer, $\mathrm{pH} 6.0$ for CD68. Non-specific protein binding was blocked using $20 \%$ swine serum at room temperature for 30 minutes, and then antibodies specific to CD3 (dilution 1:100; MCA1477, Bio-Rad), and CD68 (dilution 1:200; OABB00472, Aviva Systems Biology) were incubated overnight at $4^{\circ} \mathrm{C}$ (Leslie et al., 2020). The following day slides were washed with PBS and then incubated with the appropriate biotinylated secondary antibody; swine anti-rabbit 1:200 (eo353 Dako) for CD68 or goat antirat 1:200 (STAR80B Serotec) for CD3. After washing, slides were then incubated with Vectastain Elite ABC Reagent (Vector Laboratories). Antigens were visualised using DAB peroxidase substrate kit (Dako) and counterstained with Mayer's haematoxylin. The negative control was obtained by the replacement of primary antibody with PBS. A Nikon ECLIPSE 
material acquisition at $100 x$ and $200 x$ magnification. Irrespective of intensity, the percentages of positive cells versus total cell number were calculated using fifteen random fields per liver section in 6 mice per genotype. ImageJ (Fiji) was used for analysis as published previously (Marin-Rubio et al., 2019). Immunohistochemistry was analysed using an unpaired two-tailed t-test using GraphPad Prism (version 8.0.1).

\section{ELISA}

Cells were seeded in a 96-well plate and infected with S. aureus or L. monocytogenes at a $\mathrm{MOI}$ of 10 or 25 (as indicated). The supernatant was collected at $6 \mathrm{~h}$ post-infection and centrifuged down. ELISA for TNF- $\alpha$ (DuoSet mouse ELISA kits from R\&D Systems) were performed according to manufacturer's instruction.

\section{DiGly enrichment of ubiquitylated phagosomal peptides}

PTMScan ubiquitin remnant motif (K-ع-GG) kit (Cell Signalling Technology, cat. no. 5562)

was used according to manufacturer's instruction. All steps were performed in LoBind tubes. Phagosomal samples were prepared and digested as described above but desalting of samples was tC18 SepPak cartridge (Waters) as described by the manufacturer. K- $\varepsilon$-GG beads enrichment of peptides was performed as described by (Udeshi et al., 2013). Briefly, K- $\varepsilon-G G$ beads were cross-linked in cross-linking buffer of $100 \mathrm{mM}$ sodium borate $(\mathrm{pH} 9.0)$

710 with freshly added $20 \mathrm{mM}$ DMP. Antibody was incubated with cross-linking buffer for 30 minutes at RT with gentle end-over-end rotation. Reaction was stopped by washing beads in antibody blocking buffer (200 mM ethanolamine). After washing beads were incubated in antibody blocking buffer for 2 hours at $4^{\circ} \mathrm{C}$ with gentle rotation. Cross-linked antibody was washed three times in ice-cold IAP buffer (50 mM MOPS ( $\mathrm{pH} 7.2), 10 \mathrm{mM}$ sodium phosphate

715 and $50 \mathrm{mM} \mathrm{NaCl}$ ). Dried down peptides were resuspended in ice-cold IAP buffer and centrifuged down to remove insoluble material. Supernatant was added to K-ع-GG beads 
containing tubes (here to $300 \mu \mathrm{g}$ phagosomal proteins add $5 \mu \mathrm{l}$ packed beads). Samples were incubated for $1 \mathrm{~h}$ at $4^{\circ} \mathrm{C}$ with gentle end-over-end rotation. Samples were centrifuged down at $800 \times \mathrm{g}$ for $1 \mathrm{~min}$ at $4^{\circ} \mathrm{C}$ and supernatant was removed. Beads were washed twice in IAP buffer followed by three washes in ice-cold PBS. For K-ع-GG peptide elution after the final wash $50 \mu \mathrm{l}$ of $0.15 \%(\mathrm{v} / \mathrm{v})$ TFA was used gently mixed and incubated at RT for 5 minutes. Samples were centrifuged and supernatant was collected in fresh tubes. Elution step was repeated and collected supernatant was cleaned up with StageTip desalting columns (Thermo-Fisher) as described by the manufacturer and dried down in a Speed-Vac concentrator (Thermo-Scientific) resuspended in $20 \mu \mathrm{L} / \mathrm{C}$ water containing $3 \%$ acetonitrile $(\mathrm{MeCN})$ (Merck) and 0.1\% FA. From this a 1:5 dilution was prepared and $4 \mu \mathrm{l}$ was injected immediately into the mass spectrometer.

\section{Preparation of ubiquitin AQUA peptides}

730 Concentrated stock of isotopically labelled internal standard (heavy) peptides (M1, M1ox, K6, K6ox, K11, K27, K29, K33, K48, K63) were purchased from Cell Signaling Technologies and Cambridge Research Biochemicals (Cleveland, United Kingdom). All peptides were stored at $-80^{\circ} \mathrm{C}$ and working stock concentration was prepared of individual peptides at 25 $\mathrm{pmol} / \mu \mathrm{l}$ in $2 \%(\mathrm{v} / \mathrm{v}) \mathrm{MeCN}, 0.1 \%(\mathrm{v} / \mathrm{v}) \mathrm{FA}$. Experimental mixture of all heavy peptides was prepared at $250 \mathrm{fmol} / \mu \mathrm{l}$ in $2 \%(\mathrm{v} / \mathrm{v}) \mathrm{MeCN}, 0.1 \%(\mathrm{v} / \mathrm{v}) \mathrm{FA}$.

\section{Absolute ubiquitin quantification by Parallel Reaction Monitoring}

PRM analysis was performed on an Orbitrap Fusion or QExactive HF mass spectrometer (Thermo-Fisher Scientific) with an Easy-Spray source coupled to an Ultimate 3000 Rapid

740 Separation LC System (Thermo-Fisher Scientific) as described before (Heunis et al., 2020).

With a $5 \mu \mathrm{l}$ full loop injection samples were loaded directly onto an EASY-Spray column (15 cm x $75 \mu \mathrm{m}$ ID, PepMap C18, $3 \mu \mathrm{m}$ particles, $100 \AA ̊$ pore size, Thermo-Fischer Scientific). 
Separation of peptides was conducted by reverse phase chromatography at a flow rate of 1 $\mu \mathrm{l} / \mathrm{min}$ (Solvent A 98\% (v/v) $\mathrm{H}_{2} \mathrm{O}, 2 \%(\mathrm{v} / \mathrm{v}) \mathrm{MeCN},(\mathrm{v} / \mathrm{v}) 0.1 \% \mathrm{FA}$ and solvent $\mathrm{B}$ was $98 \%$ (v/v) MeCN, 2\% (v/v) $\left.\mathrm{H}_{2} \mathrm{O}, 0.1 \%(\mathrm{v} / \mathrm{v}) \mathrm{FA}\right)$. After LC injection peptides were resolved with an isocratic gradient of $0.1 \%$ of solvent B (10 minutes), then an increase of $0.1 \%$ to $25.5 \%$ of solvent B for over 41 minutes and finished with a 5 minutes wash of $90 \%$ solvent B to wash off any contaminations. Orbitrap Fusion mass spectrometer was operated in "tMS2" targeted mode to detect ubiquitin peptides. Included $\mathrm{m} / \mathrm{z}$ values were selected by quadrupole, with 4 $\mathrm{m} / \mathrm{z}$ isolation window, with maximum injection time of $100 \mathrm{~ms}$ and a maximum AGC target of 5e4. HCD fragmentation was performed at $30 \%$ collision energy. MS/MS fragments were detected in the Orbitrap mass analyser at a $200 \mathrm{~m} / \mathrm{z}$ resolution. Quantification of ubiquitylated peptides was done with Skyline (version 3.5.0.9191). To avoid interferences extracted ion chromatogram of MS/MS for precursor ion was adjusted manually.

\section{Sample preparation and mass spectrometry analysis}

Phagosomal proteins from RAW264.7 cells were extracted in 1\% sodium 3-[(2-methyl-2undecyl-1,3-dioxolan -4-yl)methoxy]-1-propanesulfonate (commercially available as RapiGest, Waters) in $50 \mathrm{mM}$ Tris (Sigma) $\mathrm{pH}$ 8.0, supplemented with $5 \mathrm{mM}$ of tris(2carboxyethyl)phosphine (TCEP). Samples were heated at $65^{\circ} \mathrm{C}$ for 5 minutes and afterwards alkylated with $10 \mathrm{mM}$ iodoacetamide (Sigma) for 20 minutes in the dark. Dithiothreitol (DTT) of $20 \mathrm{mM}$ was added for 20 minutes to quench alkylation. Protein concentrations were determined using EZQ protein quantitation kit (Molecular Probes). Samples were then diluted to $0.1 \%$ RapiGest in $50 \mathrm{mM}$ Tris/HCL and digested using Trypsin Gold (Promega). RapiGest was removed by adding trifluoroacetic acid (TFA, Sigma) to a final concentration of $1 \%$, shaking the samples at $37^{\circ} \mathrm{C}$ for $1 \mathrm{~h}$ and spinning them at $14,000 \mathrm{xg}$ for $30 \mathrm{~min}$. Peptides were desalted by solid phase extraction (SPE) using C-18 Micro Spin columns as described by the manufacture's instruction (The Nest Group). Samples eluted from Micro 
Spin columns were dried down in SpeedVac concentrator (Thermo Scientific) and if needed stored at $-80^{\circ} \mathrm{C}$.

Phagosomes from BMDMs were lysed in 5\% SDS in $50 \mathrm{mM}$ TEAB pH 7.5. Ten $\mu \mathrm{g}$ protein was processed for proteomic analysis using the suspension trapping (S-Trap) sample preparation method (ProtiFi) as previously described (Heap et al., 2021). Samples were dried and stored at $-80^{\circ} \mathrm{C}$.

\section{Mass spectrometry analysis}

For mass spectrometry analysis peptides were resuspended in HPLC-grade water containing $2 \% \mathrm{MeCN}$ and $1 \%$ TFA to make a final concentration of $0.5 \mu \mathrm{g} / \mu \mathrm{l} .4 \mu \mathrm{l}$ of samples were injected for analysis. Peptides were separated using $50 \mathrm{~cm}$ Acclaim PepMap 100 analytical column $(75 \mu \mathrm{m}$ ID, $3 \mu \mathrm{m}$ C18) in conjunction with a Pepmap trapping column $(100 \mu \mathrm{m} \times 2 \mathrm{~cm}, 5 \mu \mathrm{m} \mathrm{C18})($ Thermo Scientific) analysed with Orbitrap Fusion Tribrid mass spectrometer (Thermo-Fisher Scientific). A three-hour gradient was performed with $3 \%$ solvent B to $35 \%$ solvent B (solvent A: $3 \% \mathrm{MeCN}, 0.1 \% \mathrm{FA}$; solvent B: $80 \% \mathrm{MeCN}, 0.08 \%$ FA). Settings for data acquisition were MS1 with 120,000 resolution, scan range 400-1600, charge state 2-5, AGC target of 200,000 and dynamic exclusion of 60 ms with repeat count 1. Peptide ions were fragmented using HCD (35\% collision energy) with a resolution of 15,000 , and AGC target of 50,000 with a maximum injection of $60 \mathrm{~ms}$. The whole duty cycle was set to $2.5 \mathrm{~s}$ during which the instrument performed "top speed" analysis.

Peptides from BMDM phagosomes were dissolved in $2 \% \mathrm{MeCN}$ containing $0.1 \%$ TFA, and each sample was independently analysed on an Orbitrap Fusion Lumos Tribrid mass spectrometer (Thermo Fisher Scientific), connected to an UltiMate 3000 RSLCnano System (Thermo Fisher Scientific). Peptides $(1 \mu \mathrm{g})$ were injected on a PepMap 100 C18 LC trap column $(300 \mu \mathrm{m} I \mathrm{ID} \times 5 \mathrm{~mm}, 5 \mu \mathrm{m}, 100 \AA)$ followed by separation on an EASY-Spray nanoLC C18 column $(75 \mu \mathrm{m}$ ID $\times 50 \mathrm{~cm}, 2 \mu \mathrm{m}, 100 \AA)$ at a flow rate of $300 \mathrm{nl} / \mathrm{min}$. Solvent $A$ was $0.1 \% \mathrm{FA}$ and solvent $\mathrm{B}$ was $80 \% \mathrm{MeCN}$ containing $0.1 \% \mathrm{FA}$. The gradient used for analysis of samples was as follows: solvent $B$ was maintained at $3 \%$ for $5 \mathrm{~min}$, followed by 
an increase from 3 to $35 \%$ B in $180 \mathrm{~min}, 35-90 \%$ B in $0.5 \mathrm{~min}$, maintained at $90 \% \mathrm{~B}$ for $4 \mathrm{~min}$, followed by a decrease to $3 \% \mathrm{~B}$ in $0.5 \mathrm{~min}$ and equilibration at $3 \% \mathrm{~B}$ for $10 \mathrm{~min}$. The Orbitrap Fusion Lumos was operated in positive-ion data-dependent mode. The precursor ion scan was performed in the Orbitrap in the range of $400-1,600 \mathrm{~m} / \mathrm{z}$ with a resolution of 120,000 at $200 \mathrm{~m} / \mathrm{z}$, an AGC target of 400,000 and an ion injection time of $50 \mathrm{~ms}$. MS/MS spectra were acquired in the linear ion trap using Rapid scan mode after HCD fragmentation. An HCD collision energy of $30 \%$ was used, the AGC target was set to 10,000 and dynamic injection time mode was allowed. The number of MS/MS events between full scans was determined on-the-fly to maintain a $3 \mathrm{~s}$ fixed duty cycle.

805

\section{Proteome quantification}

Label-free quantification was performed using MaxQuant (v.1.5.7.4 (IFN-y experiment) or v.1.6.3.4 (RNF115 KO)) with the following modifications: fixed modification: carbamidomethyl (C); variable modifications oxidation (M), acetylation (protein N-terminus), Deamidation (NQ), 810 Glu->pyro-Glu, Ubiquitylation (GG, LRGG); label-free quantitation with minimum ratio count 2; maximum 5 modifications per peptide, and 2 missed cleavages. Searches were conducted using a murine Uniprot-Trembl database (downloaded March 26 2016, 28,245 entries (IFN-y experiment) or downloaded May 5 2019, 25,231 entries (RNF115 KO)) and a list of common contaminants. Identifications were filtered at a $1 \%$ false-discovery rate (FDR).

815 Quantification used only razor and unique peptides with a minimum ratio count of 2. "Requantify" was enabled. "Match between runs" was used with alignment time window 20 min and match time window $0.7 \mathrm{~min}$. LFQ intensities were used for data analyses.

\section{Data analysis}

820 Statistical analyses of most data was performed in GraphPad prism v9.0.2. Statistical data analysis of proteomics data was performed in Perseus (v.1.5.1.1 or 1.6.6.0) (Tyanova et al., 
2016) or in the R statistical programming language (https://www.r-project.org/) using the LIMMA (Ritchie et al., 2015) and DEqMS (Zhu et al., 2020) packages. Contaminants were removed from data set. Using LFQ Intensities from MaxQuant analysis protein ratios were generated, logarithmized and significance of changes was analysed by using Student t-test analysis $(\mathrm{p}<0.05)$. Imputation was used at standard settings. GO-term enrichment analysis was performed using DAVID GO (v. 6.7) (Jiao et al., 2012). Here significantly changed proteins (fold change $>2, p<0.05$ ) were analysed against the background of all identified proteins. Networks were retrieved from String Database (Szklarczyk et al., 2015).

\section{Data availability}

The mass spectrometry proteomics data have been deposited to the ProteomeXchange Consortium (Deutsch et al., 2017) via the PRIDE partner repository (Perez-Riverol et al., 2019) with the data set identifier: PXD026843. The data can be access using the Username: reviewer_pxd026843@ebi.ac.uk and the password: CUtZ5m3x 


\section{Acknowledgements}

MT dedicates this paper to Rolf Wehler who taught him scientific thinking. We would like to thank the DNA cloning, protein production, antibody production, DNA sequencing facility, tissue culture and mass spectrometry teams of the MRC Protein Phosphorylation and Ubiquitylation 840 Unit for their support. We would like to thank Helen Wang and Tracy Palmer for providing bacterial strains, Axel Knebel and James Hastie for protein production and Thomas Macartney for support with the CRISPR work. We would like to thank MRC Mary Lyon Centre for providing the RNF115 KO mouse. We would like to thank Helen Walden for identifying the W259A mutation of RNF115. This work was funded by Medical Research Council UK (MC_UU_12016/5), Newcastle University start-up funding and a Wellcome Trust Investigator Award to MT (215542/Z/19/Z). AH is funded by the Knut and Alice Wallenberg Foundation.

\section{Author contributions}

OBG, TH and AH performed most experiments; JP, JLMR, DF and FO performed additional experiments; OBG, TH, JP and MT performed data analysis; MT and AH designed experiments and acquired funding; MT, OBG and $\mathrm{AH}$ wrote the paper with contributions of all authors.

\section{Declaration of Interests}

F.O. is a director and shareholder in Fibrofind limited. The other authors declare no competing interests. 


\section{References}

860 Ashida H, Kim M, Sasakawa C (2014) Exploitation of the host ubiquitin system by human bacterial pathogens. Nat Rev Microbiol 12: 399-413

Boulais J, Trost M, Landry CR, Dieckmann R, Levy ED, Soldati T, Michnick SW, Thibault P, Desjardins M (2010) Molecular characterization of the evolution of phagosomes. Mol Syst Biol 6: 423

865 Brown GC, Vilalta A, Fricker M (2015) Phagoptosis - Cell Death By Phagocytosis - Plays Central Roles in Physiology, Host Defense and Pathology. Curr Mol Med 15: 842-51

Burger AM, Gao Y, Amemiya Y, Kahn HJ, Kitching R, Yang Y, Sun P, Narod SA, Hanna WM, Seth AK (2005) A novel RING-type ubiquitin ligase breast cancer-associated gene 2 correlates with outcome in invasive breast cancer. Cancer Res 65: 10401-12

870 Colomer-Lluch M, Serra-Moreno R (2017) BCA2/Rabring7 Interferes with HIV-1 Proviral Transcription by Enhancing the SUMOylation of IkappaBalpha. J Virol 91

Dean P, Heunis T, Hartlova A, Trost M (2019) Regulation of phagosome functions by posttranslational modifications: a new paradigm. Curr Opin Chem Biol 48: 73-80

Deutsch EW, Csordas A, Sun Z, Jarnuczak A, Perez-Riverol Y, Ternent T, Campbell DS, 875 Bernal-Llinares M, Okuda S, Kawano S, Moritz RL, Carver JJ, Wang M, Ishihama Y, Bandeira N, Hermjakob H, Vizcaino JA (2017) The ProteomeXchange consortium in 2017: supporting the cultural change in proteomics public data deposition. Nucleic Acids Res 45: D1100-D1106

Dill BD, Gierlinski M, Hartlova A, Arandilla AG, Guo M, Clarke RG, Trost M (2015)

880 Quantitative proteome analysis of temporally resolved phagosomes following uptake via key phagocytic receptors. Mol Cell Proteomics 14: 1334-49

Erpapazoglou Z, Walker O, Haguenauer-Tsapis R (2014) Versatile roles of k63-linked ubiquitin chains in trafficking. Cells 3: 1027-88

Flannagan RS, Heit B, Heinrichs DE (2016) Intracellular replication of Staphylococcus aureus in mature phagolysosomes in macrophages precedes host cell death, and bacterial escape and dissemination. Cell Microbiol 18: 514-35

Frankel EB, Audhya A (2018) ESCRT-dependent cargo sorting at multivesicular endosomes. Semin Cell Dev Biol 74: 4-10 
Guo M, Hartlova A, Gierlinski M, Prescott A, Castellvi J, Losa JH, Petersen SK, Wenzel UA,

890 Dill BD, Emmerich CH, Ramon YCS, Russell DG, Trost M (2019) Triggering MSR1 promotes JNK-mediated inflammation in IL-4-activated macrophages. EMBO J 38

Haglund K, Dikic I (2012) The role of ubiquitylation in receptor endocytosis and endosomal sorting. J Cell Sci 125: 265-75

Hartlova A, Peltier J, Bilkei-Gorzo O, Trost M (2017) Isolation and Western Blotting of Latex-

895 Bead Phagosomes to Track Phagosome Maturation. Methods Mol Biol 1519: 241-248

Heap RE, Gant MS, Lamoliatte F, Peltier J, Trost M (2017) Mass spectrometry techniques for studying the ubiquitin system. Biochem Soc Trans 45: 1137-1148

Heap RE, Marin-Rubio JL, Peltier J, Heunis T, Dannoura A, Moore A, Trost M (2021)

Proteomics characterisation of the L929 cell supernatant and its role in BMDM

900 differentiation. Life Sci Alliance 4

Heunis T, Lamoliatte F, Marin-Rubio JL, Dannoura A, Trost M (2020) Technical report: Targeted proteomic analysis reveals enrichment of atypical ubiquitin chains in contractile murine tissues. J Proteomics 229: 103963

Hjerpe R, Aillet F, Lopitz-Otsoa F, Lang V, England P, Rodriguez MS (2009) Efficient 905 protection and isolation of ubiquitylated proteins using tandem ubiquitin-binding entities. EMBO Rep 10: 1250-8

Hodson C, Purkiss A, Miles JA, Walden H (2014) Structure of the human FANCL RINGUbe2T complex reveals determinants of cognate E3-E2 selection. Structure 22: 337-44

Hospenthal MK, Mevissen TET, Komander D (2015) Deubiquitinase-based analysis of 910 ubiquitin chain architecture using Ubiquitin Chain Restriction (UbiCRest). Nat Protoc 10: 349-361

Ip WK, Sokolovska A, Charriere GM, Boyer L, Dejardin S, Cappillino MP, Yantosca LM, Takahashi K, Moore KJ, Lacy-Hulbert A, Stuart LM (2010) Phagocytosis and phagosome acidification are required for pathogen processing and MyD88-dependent responses to 915 Staphylococcus aureus. J Immunol 184: 7071-81

Jain N, Moeller J, Vogel V (2019) Mechanobiology of Macrophages: How Physical Factors Coregulate Macrophage Plasticity and Phagocytosis. Annu Rev Biomed Eng 21: 267-297 
Jiao X, Sherman BT, Huang da W, Stephens R, Baseler MW, Lane HC, Lempicki RA (2012) DAVID-WS: a stateful web service to facilitate gene/protein list analysis. Bioinformatics 28 : $1805-6$

Kim JJ, Lipatova Z, Segev N (2016) TRAPP Complexes in Secretion and Autophagy. Front Cell Dev Biol 4: 20

Kinchen JM, Ravichandran KS (2008) Phagosome maturation: going through the acid test. Nat Rev Mol Cell Biol 9: 781-95

Komander D, Rape M (2012) The ubiquitin code. Annu Rev Biochem 81: 203-29

Kristariyanto YA, Abdul Rehman SA, Campbell DG, Morrice NA, Johnson C, Toth R, Kulathu $Y(2015)$ K29-selective ubiquitin binding domain reveals structural basis of specificity and heterotypic nature of k29 polyubiquitin. Mol Cell 58: 83-94

Kulathu Y, Komander D (2012) Atypical ubiquitylation - the unexplored world of polyubiquitin beyond Lys48 and Lys63 linkages. Nat Rev Mol Cell Biol 13: 508-23

Lawrence DW, Kornbluth $\mathrm{J}$ (2012) E3 ubiquitin ligase NKLAM is a macrophage phagosome protein and plays a role in bacterial killing. Cell Immunol 279: 46-52

Lawrence DW, Kornbluth J (2018) Reduced inflammation and cytokine production in NKLAM deficient mice during Streptococcus pneumoniae infection. PLoS ONE 13: e0194202

935 Lee WL, Kim MK, Schreiber AD, Grinstein S (2005) Role of ubiquitin and proteasomes in phagosome maturation. Mol Biol Cell 16: 2077-90

Leslie J, Macia MG, Luli S, Worrell JC, Reilly WJ, Paish HL, Knox A, Barksby BS, Gee LM, Zaki MYW, Collins AL, Burgoyne RA, Cameron R, Bragg C, Xu X, Chung GW, Brown CDA, Blanchard AD, Nanthakumar CB, Karsdal M et al. (2020) C-Rel orchestrates energy940 dependent epithelial and macrophage reprogramming in fibrosis. Nat Metab 2: 1350-1367

Li R, Gu Z, Zhang X, Yu J, Feng J, Lou Y, Lv P, Chen Y (2020) RNF115 deletion inhibits autophagosome maturation and growth of gastric cancer. Cell Death Dis 11: 810

Liu J, Li M, Li L, Chen S, Wang X (2018) Ubiquitination of the PI3-kinase VPS-34 promotes VPS-34 stability and phagosome maturation. J Cell Biol 217: 347-360

945 Maculins T, Fiskin E, Bhogaraju S, Dikic I (2016) Bacteria-host relationship: ubiquitin ligases as weapons of invasion. Cell Res 26: 499-510 
Marin-Rubio JL, Perez-Gomez E, Fernandez-Piqueras J, Villa-Morales M (2019) S194-PFADD as a marker of aggressiveness and poor prognosis in human T-cell lymphoblastic lymphoma. Carcinogenesis 40: 1260-1268

950 Miyakawa K, Ryo A, Murakami T, Ohba K, Yamaoka S, Fukuda M, Guatelli J, Yamamoto N (2009) BCA2/Rabring7 promotes tetherin-dependent HIV-1 restriction. PLoS Pathog 5: e1000700

Mizuno K, Kitamura A, Sasaki T (2003) Rabring7, a novel Rab7 target protein with a RING finger motif. Mol Biol Cell 14: 3741-52

955 Naujoks J, Tabeling C, Dill BD, Hoffmann C, Brown AS, Kunze M, Kempa S, Peter A, Mollenkopf HJ, Dorhoi A, Kershaw O, Gruber AD, Sander LE, Witzenrath M, Herold S, Nerlich A, Hocke AC, van Driel I, Suttorp N, Bedoui S et al. (2016) IFNs Modify the Proteome of Legionella-Containing Vacuoles and Restrict Infection Via IRG1-Derived Itaconic Acid. PLoS Pathog 12: e1005408

960 Nguyen BN, Peterson BN, Portnoy DA (2019) Listeriolysin O: A phagosome-specific cytolysin revisited. Cell Microbiol 21: e12988

Nityanandam R, Serra-Moreno R (2014) BCA2/Rabring7 targets HIV-1 Gag for lysosomal degradation in a tetherin-independent manner. PLoS Pathog 10: e1004151

Otten EG, Werner E, Crespillo-Casado A, Boyle KB, Dharamdasani V, Pathe C, Santhanam 965 B, Randow F (2021) Ubiquitylation of lipopolysaccharide by RNF213 during bacterial infection. Nature 594: 111-116

Pauwels AM, Hartlova A, Peltier J, Driege Y, Baudelet G, Brodin P, Trost M, Beyaert R, Hoffmann E (2019) Spatiotemporal Changes of the Phagosomal Proteome in Dendritic Cells in Response to LPS Stimulation. Mol Cell Proteomics 18: 909-922

970 Pauwels AM, Trost M, Beyaert R, Hoffmann E (2017) Patterns, Receptors, and Signals: Regulation of Phagosome Maturation. Trends Immunol 38: 407-422

Perez-Riverol Y, Csordas A, Bai J, Bernal-Llinares M, Hewapathirana S, Kundu DJ, Inuganti A, Griss J, Mayer G, Eisenacher M, Perez E, Uszkoreit J, Pfeuffer J, Sachsenberg T, Yilmaz S, Tiwary S, Cox J, Audain E, Walzer M, Jarnuczak AF et al. (2019) The PRIDE database 975 and related tools and resources in 2019: improving support for quantification data. Nucleic Acids Res 47: D442-D450 
bioRxiv preprint doi: https://doi org/101101/2021.07.13.452284· this version posted July 15,2021 . The copyright holder for this preprin (which was not certified by peer review) is the author/funder, who has granted bioRxiv a license to display the preprint in perpetuity. It is made available under aCC-BY 4.0 International license.

Pidwill GR, Gibson JF, Cole J, Renshaw SA, Foster SJ (2020) The Role of Macrophages in Staphylococcus aureus Infection. Front Immunol 11: 620339

Qiu J, Luo ZQ (2017) Hijacking of the Host Ubiquitin Network by Legionella pneumophila. 980 Front Cell Infect Microbiol 7: 487

Ritchie ME, Phipson B, Wu D, Hu Y, Law CW, Shi W, Smyth GK (2015) limma powers differential expression analyses for RNA-sequencing and microarray studies. Nucleic Acids Res 43: e47

Ritorto MS, Ewan R, Perez-Oliva AB, Knebel A, Buhrlage SJ, Wightman M, Kelly SM, Wood NT, Virdee S, Gray NS, Morrice NA, Alessi DR, Trost M (2014) Screening of DUB activity and specificity by MALDI-TOF mass spectrometry. Nat Commun 5: 4763

Rybicka JM, Balce DR, Khan MF, Krohn RM, Yates RM (2010) NADPH oxidase activity controls phagosomal proteolysis in macrophages through modulation of the lumenal redox environment of phagosomes. Proc Natl Acad Sci U S A 107: 10496-501

990 Savina A, Jancic C, Hugues S, Guermonprez P, Vargas P, Moura IC, Lennon-Dumenil AM, Seabra MC, Raposo G, Amigorena S (2006) NOX2 controls phagosomal pH to regulate antigen processing during crosspresentation by dendritic cells. Cell 126: 205-18

Smith CJ, Berry DM, McGlade CJ (2013) The E3 ubiquitin ligases RNF126 and Rabring7 regulate endosomal sorting of the epidermal growth factor receptor. J Cell Sci 126: 1366-80

995 Swatek KN, Aumayr M, Pruneda JN, Visser LJ, Berryman S, Kueck AF, Geurink PP, Ovaa $H$, van Kuppeveld FJM, Tuthill TJ, Skern T, Komander D (2018) Irreversible inactivation of ISG15 by a viral leader protease enables alternative infection detection strategies. Proc Natl Acad Sci U S A 115: 2371-2376

Swatek KN, Usher JL, Kueck AF, Gladkova C, Mevissen TET, Pruneda JN, Skern T, 1000 Komander D (2019) Insights into ubiquitin chain architecture using Ub-clipping. Nature 572: 533-537

Szklarczyk D, Franceschini A, Wyder S, Forslund K, Heller D, Huerta-Cepas J, Simonovic M, Roth A, Santos A, Tsafou KP, Kuhn M, Bork P, Jensen LJ, von Mering C (2015) STRING v10: protein-protein interaction networks, integrated over the tree of life. Nucleic Acids Res 43: D447-52 
Trost M, English L, Lemieux S, Courcelles M, Desjardins M, Thibault P (2009) The phagosomal proteome in interferon-gamma-activated macrophages. Immunity 30: 143-54

Tsuchiya H, Tanaka K, Saeki Y (2013) The parallel reaction monitoring method contributes to a highly sensitive polyubiquitin chain quantification. Biochem Biophys Res Commun 436: 223-9

Tyanova S, Temu T, Sinitcyn P, Carlson A, Hein MY, Geiger T, Mann M, Cox J (2016) The Perseus computational platform for comprehensive analysis of (prote)omics data. Nat Methods 13: 731-40

Udeshi N, Mertins P, Svinkina T, Carr S (2013) Large-scale identification of ubiquitination 1015 sites by mass spectrometry. Nature Protocols 8: 1950-1960

van Huizen M, Kikkert M (2019) The Role of Atypical Ubiquitin Chains in the Regulation of the Antiviral Innate Immune Response. Front Cell Dev Biol 7: 392

Vozandychova V, Stojkova P, Hercik K, Rehulka P, Stulik J (2021) The Ubiquitination System within Bacterial Host-Pathogen Interactions. Microorganisms 9 responses. Immunol Rev 266: 161-74

Yates RM, Hermetter A, Russell DG (2009) Recording phagosome maturation through the real-time, spectrofluorometric measurement of hydrolytic activities. Methods Mol Biol 531: $157-71$ downregulates the degradative capacity of the phagosome. Traffic 8: 241-50

Yau R, Rape M (2016) The increasing complexity of the ubiquitin code. Nat Cell Biol 18: $579-86$

Yin Q, Han T, Fang B, Zhang G, Zhang C, Roberts ER, Izumi V, Zheng M, Jiang S, Yin X, 1030 Kim M, Cai J, Haura EB, Koomen JM, Smalley KSM, Wan L (2019) K27-linked ubiquitination of BRAF by ITCH engages cytokine response to maintain MEK-ERK signaling. Nat Commun 10: 1870

Zhang Y, Mao D, Roswit WT, Jin X, Patel AC, Patel DA, Agapov E, Wang Z, Tidwell RM, Atkinson JJ, Huang G, McCarthy R, Yu J, Yun NE, Paessler S, Lawson TG, Omattage NS, Brett TJ, Holtzman MJ (2015) PARP9-DTX3L ubiquitin ligase targets host histone H2BJ and 
bioRxiv preprint doi: https://doi.org/10.1101/2021.07.13.452284; this version posted July 15, 2021. The copyright holder for this preprint

(which was not certified by peer review) is the author/funder, who has granted bioRxiv a license to display the preprint in perpetuity. It is made available under aCC-BY 4.0 International license.

viral $3 \mathrm{C}$ protease to enhance interferon signaling and control viral infection. Nat Immunol 16: $1215-27$

Zhang ZD, Xiong TC, Yao SQ, Wei MC, Chen M, Lin D, Zhong B (2020) RNF115 plays dual roles in innate antiviral responses by catalyzing distinct ubiquitination of MAVS and MITA.

1040 Nat Commun 11: 5536

Zhu Y, Orre LM, Zhou Tran Y, Mermelekas G, Johansson HJ, Malyutina A, Anders S, Lehtio J (2020) DEqMS: A Method for Accurate Variance Estimation in Differential Protein

Expression Analysis. Mol Cell Proteomics 19: 1047-1057

1045 


\section{Supplementary data}

\section{Supplementary Figure 1}

A

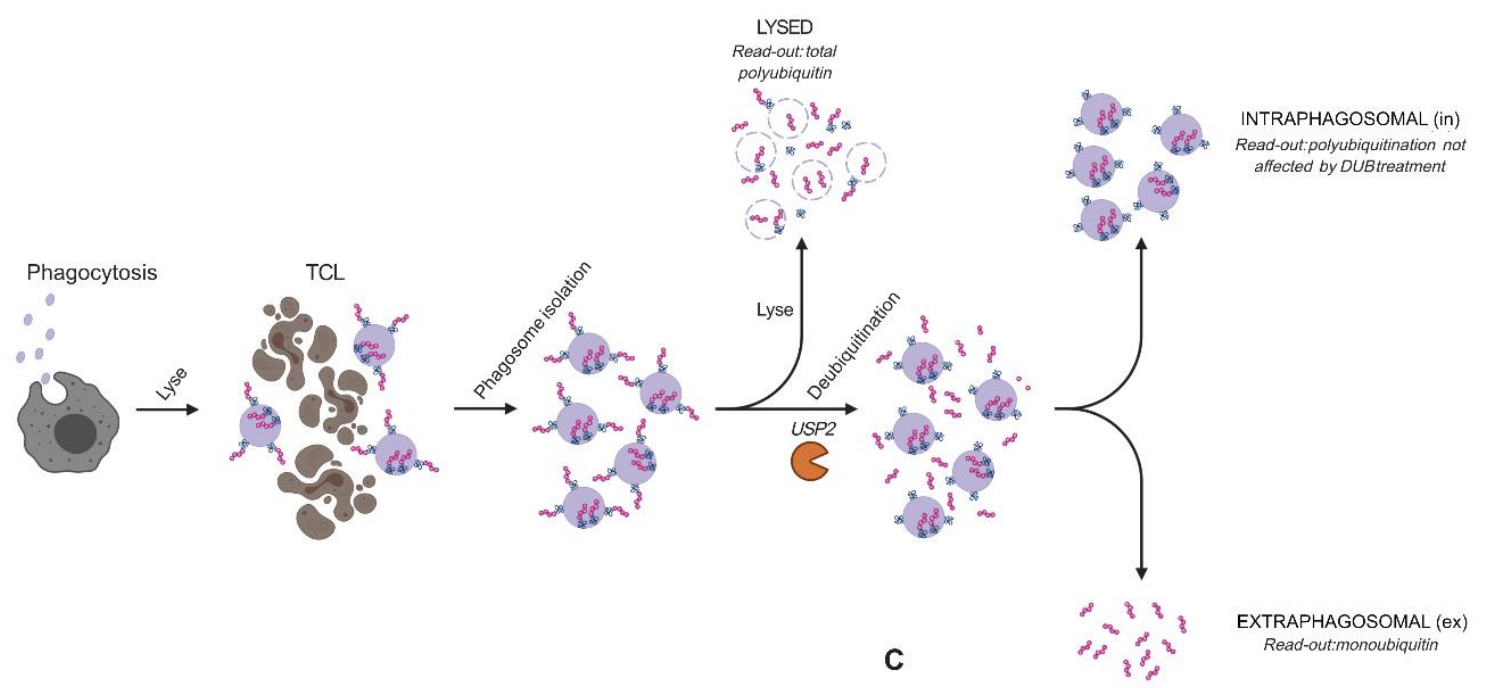

B

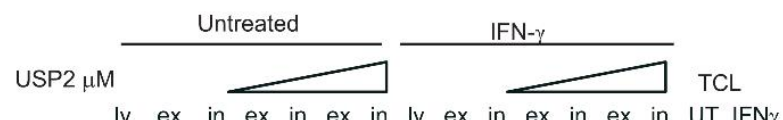

Supplementary Figure 1: Phagosomal ubiquitylation is almost entirely cytoplasmic.

(A) Workflow: phagosomes were isolated and then either lysed using a detergent containing buffer or treated with increasing concentrations of (chain unspecific) USP2 to cleave off cytoplasmic ubiquitin chains. Phagosomes were then pelleted and the supernatant or the lysed pellet was analysed by Western Blot against ubiquitin (B). iNOS serves as a control for IFN-activation. Vimentin serves as an attempt to control loading. (C) the same treatment of phagosomes with the K63-specific AMSH-LP shows that K63 chains are highly abundant on the cytoplasmic side of phagosomes. Western blots representative of two replicates. 


\section{Supplementary Figure 2}

A

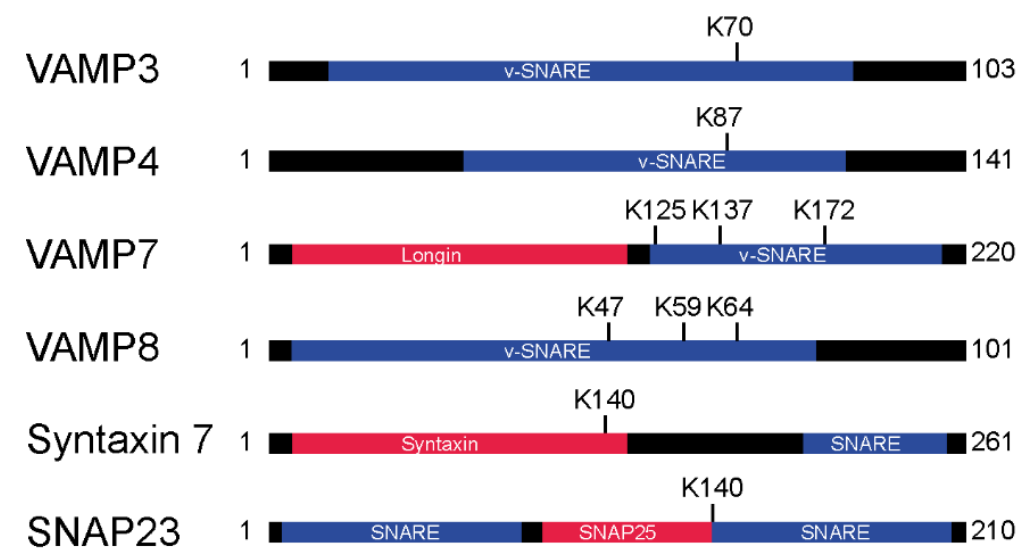

B Input TAB2 PD

AMSH-LP $\quad-\quad-+$

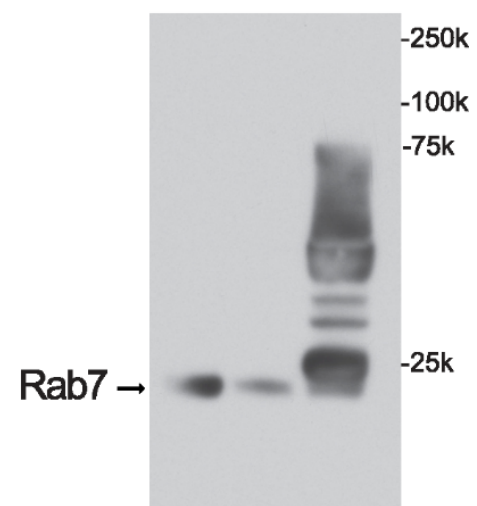

1065 Supplementary Figure 2: Ubiquitylation of vesicle trafficking proteins. (A) Ubiquitylation sites of phagosomal SNARE proteins are almost entirely within SNARE domains, thereby blocking SNARE protein interactions. (B) ubiquitylation of proteins affects their detection by antibodies. As an example, Rab7 is shown. TAB2 pulldown (PD) of K63 polyubiquitylated proteins and subsequent Western blot of Rab7 shows no ubiquitylated forms of Rab7 (probably by blocking of antibody antigen). Upon AMSH-LP treatment multiple forms of ubiquitylated Rab7 appear. 


\section{Supplementary Figure 3}

A

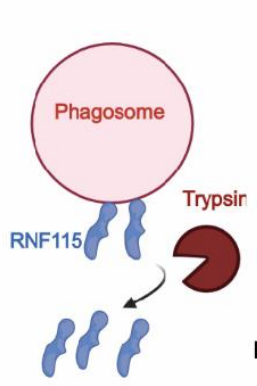

C

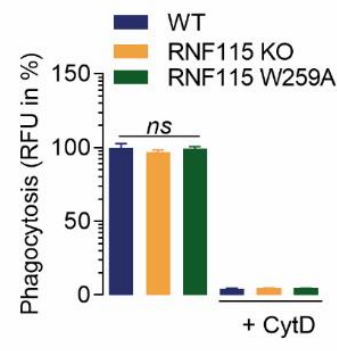

Phagosome

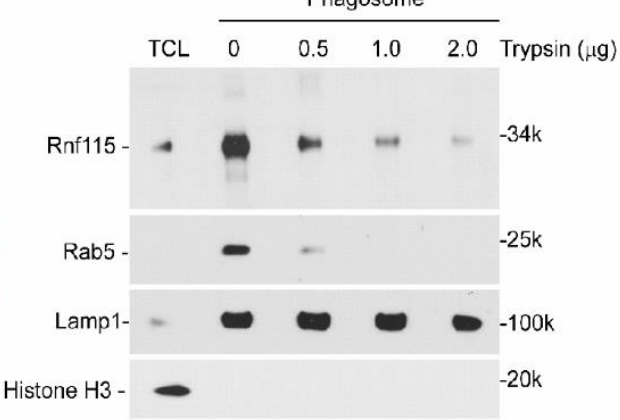

D

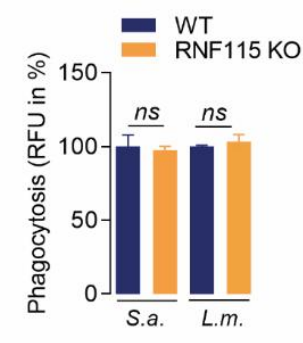

Supplementary Figure 3: Phagosomal RNF115. (A) RNF115 is located on the cytoplasmic side of phagosomes. Treatment of isolated phagosomes with increasing amounts of Trypsin shoes a reduction of RNF115. Rab5, a cytoplasmic membrane bound protein and LAMP1, a transmembrane protein, serve as controls. Histone $\mathrm{H} 3$ serves as purity control.

Representative blot of two replicates. (B) Immunoprecipitation (IP) of RNF115 from WT and RNF115 knock-out RAW263.7 cells (KO) shows that RNF115 is absent in the KO cells. (C) Loss of RNF115 (KO) or mutation of the E2 binding site (W259A) does not affect uptake of carboxylated beads or (D) bacteria. S.a. Staphylococcus aureus; L.m. Listeria monocytogenes). 